\begin{tabular}{|c|c|}
\hline Title & Recent progress in integration of III-V nanowire transistors on $\mathrm{Si}$ substrate by selective area growth \\
\hline Author(s) & Tomioka, Katsuhiro; Fukui, Takashi \\
\hline Citation & $\begin{array}{l}\text { Journal of Physics D: A pplied Physics, } 47(39), 394001 \\
\text { https://doi.org/10.1088/0022-3727/47/39/394001 }\end{array}$ \\
\hline Issue Date & 2014-10-01 \\
\hline Doc URL & http:/hdl.handle.net/2115/57448 \\
\hline Rights(URL) & http:///reativecommons.org/icenses/by $\beta .0$ \\
\hline Type & article \\
\hline File Information & 0022-3727_47_39_394001.pdf \\
\hline
\end{tabular}

Instructions for use 
Recent progress in integration of III-V nanowire transistors on Si substrate by selective-area growth

This content has been downloaded from IOPscience. Please scroll down to see the full text.

2014 J. Phys. D: Appl. Phys. 47394001

(http://iopscience.iop.org/0022-3727/47/39/394001)

View the table of contents for this issue, or go to the journal homepage for more

Download details:

IP Address: 133.87.175.68

This content was downloaded on 20/11/2014 at 07:05

Please note that terms and conditions apply. 


\title{
Recent progress in integration of III-V nanowire transistors on Si substrate by selective-area growth
}

\author{
Katsuhiro Tomioka ${ }^{1,2,3}$ and Takashi Fukui ${ }^{1,2}$ \\ ${ }^{1}$ Graduate School of Information Science Technology, Hokkaido University, North 14 West 9, \\ Sapporo 060-0814, Japan \\ ${ }^{2}$ Research Center for Integrated Quantum Electronics (RCIQE), Hokkaido University, North 13 West 8 , \\ Sapporo 060-8628, Japan \\ ${ }^{3}$ Japan Science and Technology Agency-PRESTO, 4-1-8, Kawaguchi, Saitama 332-0012, Japan \\ E-mail: tomioka@rciqe.hokudai.ac.jp
}

Received 8 April 2014, revised 28 May 2014

Accepted for publication 24 June 2014

Published 11 September 2014

\begin{abstract}
We report on the recent progress in electronic applications using III-V nanowires (NWs) on $\mathrm{Si}$ substrates using the selective-area growth method. This method could align vertical III-V NWs on Si under specific growth conditions. Detailed studies of the III-V NW/Si heterointerface showed the possibility of achieving coherent growth regardless of misfit dislocations in the III-V/Si heterojunction. The vertical III-V NWs grown using selective-area growth were utilized for high performance vertical field-effect transistors (FETs).

Furthermore, III-V NW/Si heterointerfaces with fewer misfit dislocations provided us with a unique band discontinuity with a new functionality that can be used for the application of tunnel diodes and tunnel FETs. These demonstrations could open the door to a new approach for creating low power switches using III-V NWs as building-blocks of future nanometre-scaled electronic circuits on Si platforms.
\end{abstract}

Keywords: III-V nanowires, epitaxy, FET, tunnel FET

(Some figures may appear in colour only in the online journal)

\section{Introduction}

III-V compound semiconductor nanowires (NWs) have attracted a lot of attention as building blocks for future electronic and optical devices [1-6]. InAs and InGaAs NWs are especially promising channel materials for nextgeneration field-effect transistors (FETs), because these III-V NWs have a lower electron effective mass and higher electron mobility, and their NW geometries are feasible for use in surrounding-gate architecture, in which all the surfaces around the NW are wrapped by gate metal. These III-V NWs can enhance the ON-state current under a lower supply voltage, and the surrounding-gate structure suppresses the OFF-state

(i) Content from this work may be used under the terms of the Creative Commons Attribution 3.0 licence. Any further distribution of this work must maintain attribution to the author(s) and the title of the work, journal citation and DOI. leakage current as compared to that of $\mathrm{Si}$ metal-oxidesemiconductor FETs (MOSFETs) and Si fin FETs. The recent studies on III-Vs as alternative channels for future FETs have been exceedingly common in the field of $\mathrm{Si}$ complementary MOS (CMOS) technologies [7-9]. However, the vertical III-V NWs on Si substrates as alternative channel materials have not been aggressively investigated using the bottom-up growth approach [10-15], because the channelformation technique had some difficulties in suppressing formation of crystal defects due to mismatches such as lattice constants and polarity. Mismatches in the lattice constant and thermal expansion coefficients form defects such as misfit and threading dislocations. The mismatches in polarity between polar III-V NWs and non-polar Si randomize the growth direction along an equivalent orientation and forms anti-phase defects. 
Recent progress in the heteroepitaxy of III-V NWs on Si such as metal-catalysed [16], self-catalysed vapour-liquidsolid (VLS) [17], and selective-area growth [18] have been solving these problems due to their nanometre-scale footprints. Since Märtensson's pioneering works in 2004 [19], the heteroepitaxy of As/P/Sb-related III-V NWs on Si has been increasing. In 2011, we summarized the progress in the heteroepitaxy of III-V NWs on Si at that time, which mainly focused on selective-area growth and their device applications [20]. Topics concerning the III-V NWs on $\mathrm{Si}$ are attracting much attention today. Most of the reports have focused on the synthesis of the NWs on Si. So far, the growth of GaAs [21-24, 29-38, 53-62, 82-98, 118, 119, 126, 129], InP [49-52, 76-80, 108-112, 122, 123], InAs [10-12, 14, 15, 25-27, 39-47, 68-70, 73,99-101, 124, 126, 130, 142, 144], InSb [117], and ternary alloys such as InGaAs [13, 48, 7175, 102-107, 120,121, 139], GaAsP [81,114,115], InAsP [113] and GaAsSb or InGaSb [116,125] NWs on Si have been reported, and these NWs were grown by using metal-catalysed VLS [23, 24, 30,31,49-51,55,62, 65-67, 70, 77, 79, 81, 83, 104, 106, 109, 111, 112, 127-129], self-catalysed VLS $[21,22,27-29,32-38,40,41,43-46,50$, $53,54,57-61,63,64,71,74,78,80,82,85,86,88-94,96-98$, $103,105,107,108,110,113-119,123-126]$, and catalyst-free selective-area growth $[25,26,39,47,56,68,69,72,73,75,84$, $87,95,99-102,120-122,142,144]$. The most interesting phenomenon of the nanometre-scaled epitaxy is suppression of misfit and threading dislocations, because the nanometrescaled footprints moderately relax the lattice mismatches. For the selective-area growth, the formation of misfit dislocations in the III-V NWs on a Si substrate have been systematically characterized as a function of the NW diameter [130]. Also, the mask layer eliminates the propagation of threading dislocations inside the grown NW material.

The device applications can be divided into two categories: simple integration and fusion of III-V NWs with $\mathrm{Si}$ as a new heterointerface. Basic electronic and optical devices such as light-emitting diodes (LEDs) [34] and vertical FETs $[10-15,47,75,102]$ on $\mathrm{Si}$ have been reported as the simple integration, and high performance devices such as high-electron mobility transistors (HEMTs) $[75,102]$ have been demonstrated on Si substrates. In the fusion of III-V NWs with $\mathrm{Si}$, heterojunctions of III-V/Si with fewer dislocations present a unique band discontinuity across the III-V NW/Si heterojunction. Electronic and optoelectronic devices using III-V NW/Si heterojunctions such as tunnel diodes $[42,73,121,144]$, and tunnel FETs (TFETs) $[39,68,120,130,142,144]$ have been demonstrated.

We are now reporting on our recent progress in the heteroepitaxy of III-V NWs on $\mathrm{Si}$, specifically focusing on the details on the selective-area growth of vertical InGaAs NWs on Si and Zn-doped InAs NWs on Si substrates, and our demonstration of electronic devices such as vertical FETs, tunnel diodes, and TFETs using III-V NWs on Si and III-V NW/Si heterojunctions formed using selective-area MOVPE.

\section{Selective-area growth of vertical InGaAs NWs on $\mathrm{Si}$}

The formation of a (1 11 1)B-oriented surface on a Si surface is important for aligning vertical III-V NWs on Si because almost all of the III-V NWs grow preferentially along the $\left\langle\begin{array}{llll}1 & 1 & 1\end{array}\right\rangle$ direction. The (1 111 )B-oriented surfaces on a Si(lllll) surface are the group-V incorporated $\mathrm{Si}\left(\begin{array}{lll}1 & 1 & 1\end{array}\right)$ and group-III terminated Si(1 111$)$ surfaces [131, 132]. These (1 111$)$ B-oriented surfaces should be formed just before the growth of III-V NWs. The selective-area growth of III-V NWs on Si requires stricter conditions, since the surface area for NW growth is restricted to within the nanometre-scaled region. Moreover, the coexistence of the (1 111$) \mathrm{B}$ - and (1 111$) \mathrm{A}$-oriented surfaces in the selective-area growth forms hillock structures instead of forming anti-phase defects. This growth behaviour can be prominently observed in the case of the selective-area growth of vertical InGaAs NWs on $\mathrm{Si}$. We recently reported on how to align the vertical InGaAs NWs on Si substrates [75]. However, the detailed characterization of the InGaAs NWs on Si by using selective-area growth has not yet been reported on. In this section, we focus on the details of this selective-area growth.

InGaAs is widely used in high performance electronic devices such as planar HEMTs and optical devices used for infra-red lasers and passive devices such as APDs because of its band-gap engineering with $\mathrm{In} / \mathrm{Ga}$ ratio variation. Once the heterogeneous integration of vertical InGaAs NWs is achieved on Si substrates, the possibility of NWs for the device applications briefly mentioned above will become reality. For example, the Fermi levels within the InGaAs NWs can be changed based on the composition of the In atoms [133]. This means that Schottky barrier height can be controlled by the composition. In addition, the InGaAs NWs are expected to be used in tandem-type solar cells because their nanometrescaled cross-section would release interface strain and thus avoid introduction of misfit dislocations between the III$\mathrm{V} / \mathrm{Ge}$ interfaces. They also can be used for a wide range of wavelength charged-coupled devices (CCDs) in tandem with Si-based CCDs. Therefore, InGaAs NWs on Si would be better material systems because their one-dimensional structure and nanometre-scaled footprint can easily accommodate any lattice mismatches regardless of misfit dislocations. We investigate the epitaxial technique for aligning InGaAs NWs on Si the growth directions and positions for these applications to take full advantage of selective-area growth.

The growth conditions for the selective-area growth of vertical InGaAs NWs on $\mathrm{Si}\left(\begin{array}{lll}1 & 1 & 1\end{array}\right)$ are slightly different from those for vertical InAs and GaAs NWs on $\mathrm{Si}$. The low-temperature surface cleaning using $\mathrm{AsH}_{3}$ at $400{ }^{\circ} \mathrm{C}$ and using the flow-rate modulation epitaxy (FME) mode were effective for forming a (1 11 1)B-oriented surface and aligning vertical InAs NWs on $\mathrm{Si}\left(\begin{array}{lll}1 & 1 & 1\end{array}\right)$ for the selective-area growth of InAs NWs on Si [131]. The low-temperature surface cleaning effectively forms an As-incorporated Si surface that corresponds to the (1 111$)$ B-oriented surface. The FME mode terminates the Si dangling bond and the incorporated As atoms by using the In atoms. In addition, the low-temperature surface cleaning by $\mathrm{AsH}_{3}$ and the low-temperature buffer GaAs growth 


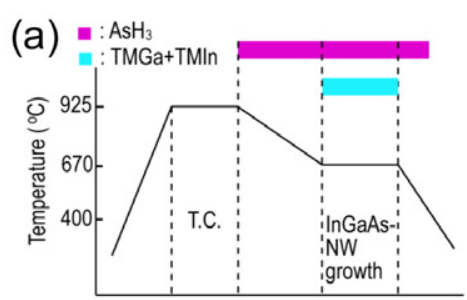

(d)

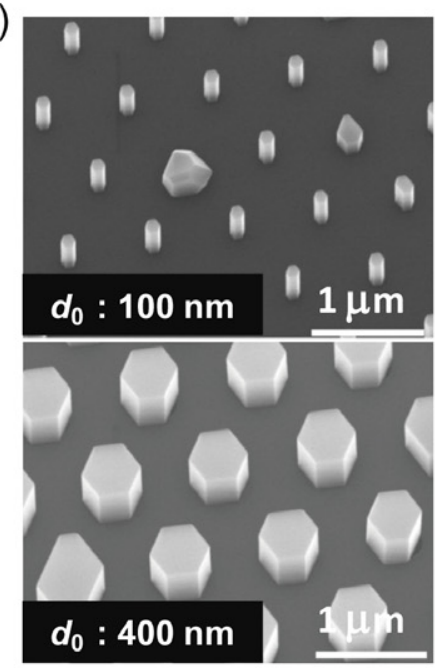

(b)

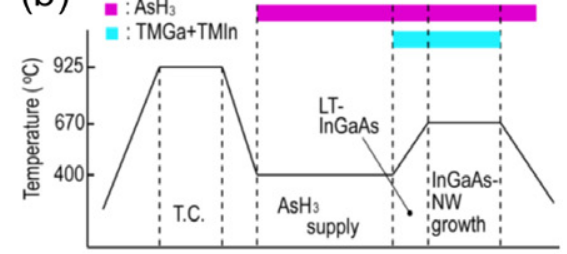

(e)

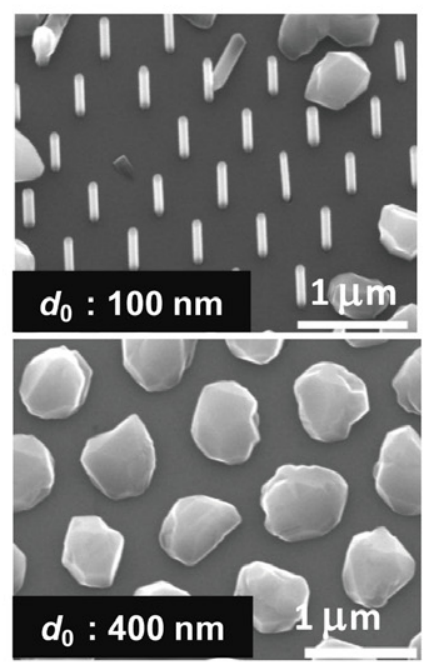

(c)

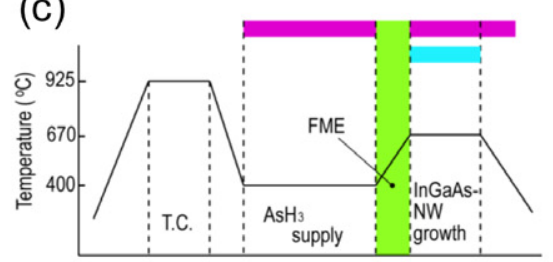

(f)
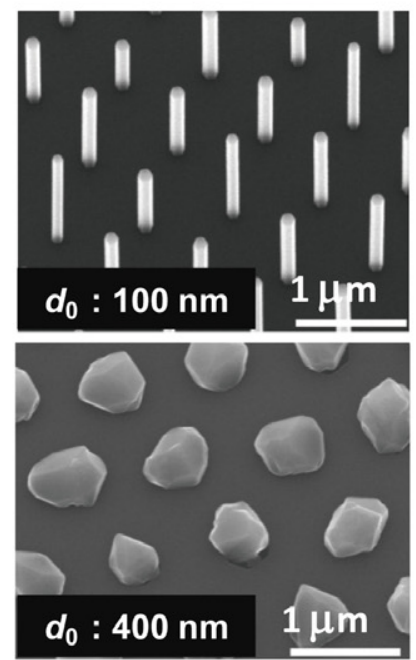

Figure 1. Growth sequences: $(a)$ conventional sequence, $(b) \mathrm{AsH}_{3}$ surface treatment at $400{ }^{\circ} \mathrm{C}$ and low-temperature (LT) InGaAs growth, (c) $\mathrm{AsH}_{3}$ surface treatment at $400{ }^{\circ} \mathrm{C}$ and flow-rate modulation epitaxy (FME), and representative SEM images of InGaAs grown by using $(d)$ the sequence in $(a),(e)$ the sequence in $(b)$, and $(f)$ the sequence in $(c)$.

were effective for aligning the vertical GaAs NWs on $\mathrm{Si}\left(\begin{array}{lll}1 & 1 & 1\end{array}\right)$ [132]. The growth condition of the vertical InGaAs NWs on $\mathrm{Si}$ is slightly different from that for InAs and GaAs NWs on Si $[131,132]$. In the InGaAs case, the bonding-energy difference of $\mathrm{Ga}-\mathrm{Si}$ and $\mathrm{In}-\mathrm{Si}$ should be taken into account for the formation of the (1 111$)$ B-oriented surface.

The (1 111$)$-oriented $\mathrm{Si}$ substrates were used as the starting substrates. First, the substrates were etched using a hydrofluoric (HF) solution and then cleaned with a socalled RCA cleaning that uses $\mathrm{SC} 1$ and $\mathrm{SC} 2$ solutions $\left(1 \mathrm{NH}_{4} \mathrm{OH}: 1 \mathrm{H}_{2} \mathrm{O}_{2}: 5 \mathrm{H}_{2} \mathrm{O}\right.$ and $1 \mathrm{HCl}: 1 \mathrm{H}_{2} \mathrm{O}_{2}: 6 \mathrm{H}_{2} \mathrm{O}$ at $\left.75^{\circ} \mathrm{C}\right)$ to remove any metal particles from their surfaces. For the selective-area growth of InGaAs NWs on Si(1 111$)$, we used a lithography defined mask opening inside a $50 \times 50 \mu \mathrm{m}^{2}$ square $\mathrm{SiO}_{2}$ mask that was $20 \mathrm{~nm}$ thick. The opening diameter $\left(d_{0}\right)$ was 100 or $400 \mathrm{~nm}$. The $\mathrm{SiO}_{2}$ film was made by using thermal oxidation at $950{ }^{\circ} \mathrm{C}$. The InGaAs NWs were grown in a low-pressure (76 Torr) horizontal metal-organic vapour phase epitaxy (MOVPE) system, supplying trimethylindium (TMIn), trimethylgallium (TMGa), and arsine $\left(\mathrm{AsH}_{3}\right)$ as source materials. The partial pressures of TMIn ([TMIn]), TMGa ([TMGa]), and $\mathrm{AsH}_{3}\left(\left[\mathrm{AsH}_{3}\right]\right)$ were $9.7 \times 10^{-7}$, $5.7 \times 10^{-7}$ and $5.0 \times 10^{-4}$ atm. The growth temperature $\left(T_{\mathrm{G}}\right)$ was $670^{\circ} \mathrm{C}$, and the growth time was $20 \mathrm{~min}$.

Figure 1 shows several growth conditions for the InGaAs NWs on a Si substrate by using selective-area growth and a summary of the representative growth results of InGaAs on Si with opening diameters of 100 and $400 \mathrm{~nm}$ under each growth condition. We commonly used thermal cleaning at $925^{\circ} \mathrm{C}$ in a $\mathrm{H}_{2}$ ambient for each growth conditions, which is necessary to thermally evaporate the native oxide and to form the $\operatorname{Si}\left(\begin{array}{lll}1 & 1 & 1\end{array}\right) 1 \times 1$ surface reconstruction. In figure $1(a)$, the substrate was cooled to $T_{\mathrm{G}}=670^{\circ} \mathrm{C}$ in the $\mathrm{AsH}_{3}$ ambient, and then the InGaAs NW growth was resumed. Figure 1(b) shows a similar growth sequence to those of the selective-area growth of vertical GaAs NWs on Si [132]. The sequence contains the low-temperature surface cleaning by $\mathrm{AsH}_{3}$ to form an As-incorporated Si(1 11 l) surface and low-temperature InGaAs growth. Figure 1 $(c)$ follows the growth sequence of the selective-area growth of vertical InAs NWs on Si using the FME mode [131].

Figure $1(d)$ shows the representative growth results of the growth sequence shown in figure $1(a)$. The NW growth yield when $d_{0}=100 \mathrm{~nm}$ was $87 \%$ and the hillock growth yield was $13 \%$. Among the NW growths, the vertical InGaAs NW growth direction percentage was almost $100 \%$. The hillock growth resulted from the co-existence of the (111)A and (1 11 1)B orientations inside the openings. For $d_{0}=400 \mathrm{~nm}$, the faceting growth of non-uniformed hexagons appeared. These results indicate that the $\left(\begin{array}{lll}1 & 1 & 1\end{array}\right) \mathrm{B}$-oriented surface formation was insufficient when there was a small opening diameter and the As-terminated Si surface was formed during the cooling down process, but the formation of the (111)A-oriented surface was almost suppressed for the large openings. This implies that the In or $\mathrm{Ga}$ atom termination when forming a (1 11 1)B orientation was dominant under this growth sequence.

Figure 1(e) depicts the InGaAs growth results of the sequence in figure $1(b)$. Under the growth sequence for $d_{0}=100 \mathrm{~nm}$, the percentage of vertical and tilted InGaAs NW growths was 76 and $7 \%$. The percentage of the 
(a)
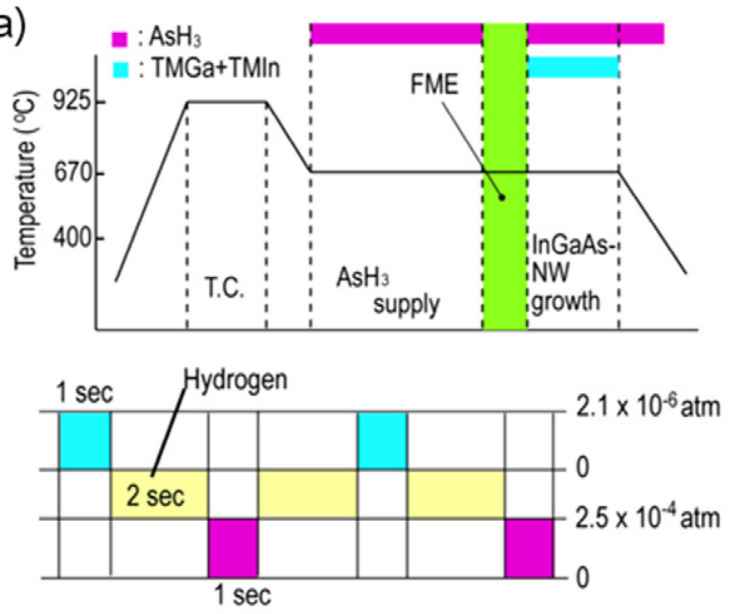

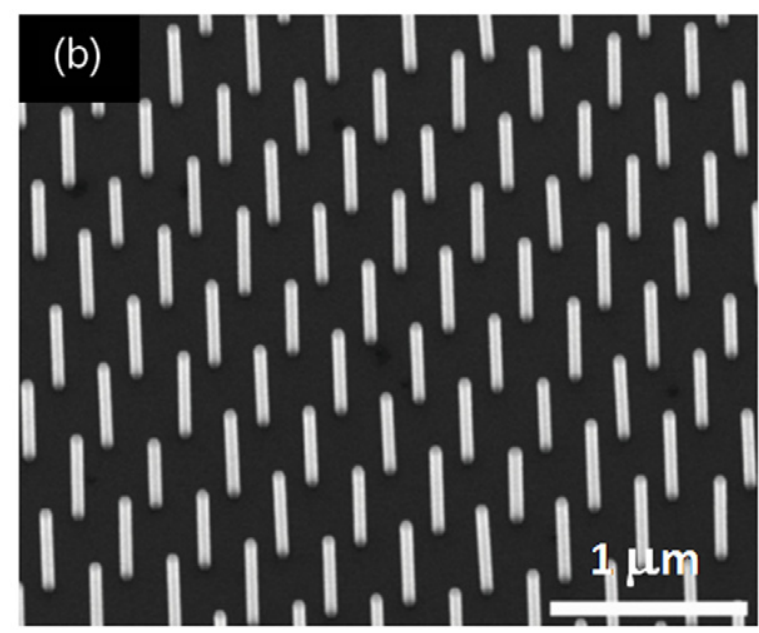

Figure 2. (a) Optimum growth sequence of aligning vertical InGaAs NWs on Si (adapted from [20]). (b) Representative SEM image showing vertical InGaAs NW array on Si (adapted with permission from [20], Copyright 2011 IEEE).

hillocks was $17 \%$, and this percentage was dominant when $d_{0}=400 \mathrm{~nm}$. The growth yield of hillocks was almost the same as those shown in figure $1(d)$, but the percentage of the inclined NW growth was slightly increased, which means a (1 111$)$ A-oriented surface formation was facilitated by the growth sequence. This indicates that $70-80 \%$ of the openings were changed into a $\left(\begin{array}{lll}1 & 1 & 1\end{array}\right) \mathrm{B}$-oriented surface during the low-temperature surface cleaning by $\mathrm{AsH}_{3}$, and the (1 111$) \mathrm{A}$ oriented surface was formed during the lowtemperature InGaAs growth. The Ga-In alloy and Si were thought to enhance the thermal reactions and lead desorption. After the desorption, other (1 11 1)A surfaces were formed. The As termination against a dangling bond of $\mathrm{Si}\left(\begin{array}{lll}1 & 1 & 1\end{array}\right)$ occurred during the low-temperature InGaAs growth.

Figure $1(f)$ shows the growth results for the growth sequence in figure $1(c)$. The percentage of vertical InGaAs NWs was almost $100 \%$ when $d_{0}=100 \mathrm{~nm}$. However, the diameter and height of the vertical InGaAs NWs were not uniform. In the case of $d_{0}=400 \mathrm{~nm}$, all of the grown materials were hillock structures. This indicates that the growth sequence can moderately form a (1 111$)$ B-oriented surface and align the vertical InGaAs NWs when there is a small diameter, while the formation of a (1 111$)$ B-oriented surface was insufficient and forms hillocks due to the coalescence of multi nuclei on the (1 111$) \mathrm{A}$ and (1 111$) \mathrm{B}$ surfaces when there is a large opening diameter. Since the role of the FME mode was to terminate the remaining dangling bond on a $\mathrm{Si}\left(\begin{array}{lll}1 & 1 & 1\end{array}\right)$ surface by using group-III atoms, this mode seemed to be effective enough for terminating the dangling bonds created by In or Ga atoms for small openings. However, the termination when using group-III atoms was insufficient and As termination possibly occurred during the FME mode in case of the large openings.

According to these growth characterizations, the growth sequence in figure 1( $a$ ) and the FME in figure 1(c) are effective at forming a (1 111$) \mathrm{B}$-oriented surface for aligning vertical InGaAs NWs on a $\mathrm{Si}\left(\begin{array}{lll}1 & 1 & 1\end{array}\right)$ surface with small openings. Thus, the growth sequence was optimized, which is shown in figure 2(a) [20]. In this case, the combination of $\mathrm{AsH}_{3}$ surface treatment and the FME mode at $670{ }^{\circ} \mathrm{C}$ is important for aligning vertical $\mathrm{InGaAs} \mathrm{NWs}$ on $\mathrm{Si}$. The representative growth results are shown in figure $2(b)$. The percentage of vertical NW was almost $100 \%$. A (1 11 1)B surface orientation due to the incorporation of group- $\mathrm{V}$ atoms and a $\mathrm{Si}^{+}$surface were thought to be formed under the sequence depicted in figure $2(a)$.

The yield of the vertical InGaAs NW growth strongly depended on $\left[\mathrm{AsH}_{3}\right]$ during $\mathrm{NW}$ growth in the sequence depicted in figure 2(a). Figure 2(b) shows some typical growth results. The yield of the vertical InGaAs NWs increased to $100 \%$ when increasing $\left[\mathrm{AsH}_{3}\right]$, as shown in figures 3 and 4. This indicates that the InGaAs NWs nucleation process proceeds well when using a high $\mathrm{AsH}_{3}$, and group-III atoms, which adsorbed into Si dangling bonds to form a (1 111$) \mathrm{B}-$ oriented surface, are easily desorbed from the Si surface at higher temperatures, but high As coverage of the In/Gaterminated $\mathrm{Si}$ surface suppresses the desorption of the group-III atoms from the $\mathrm{In}-\mathrm{Si}$ and $\mathrm{Ga}-\mathrm{Si}$ bonding. For a lower $\left[\mathrm{AsH}_{3}\right]$, the desorption process for the group-III atoms was enhanced with less As coverage and the NW growth in itself failed eventually suppressed. In addition, the NW growth yield decreased to $1 \%$.

Figure 5(a) depicts a transmission electron microscopy (TEM) image of InGaAs NW with a diameter of $67 \mathrm{~nm}$. The diameter of the InGaAs NW/Si heterointerface was $33 \mathrm{~nm}$. The crystal structure of the InGaAs NW was a zinc-blende structure with many rotational twins. The frequency of the twin was distributed within three monolayers (MLs). Although the InGaAs NW had many rotational twins, no threading dislocation was observed in them. An energy dispersive $\mathrm{X}-$ ray (EDX) line-scan profile showed that the In composition was 70\% [75] and there was no diameter dependence [120]. The In composition was higher than that of the In in the vapour phase $(63 \%)$. This is because the surface diffusion lengths of In atoms on $\mathrm{SiO}_{2}$ and sidewalls of an InGaAs NW were longer than those of $\mathrm{Ga}$ atoms. Then, the number of In adatoms increased in the InGaAs NW growth. Figure $5(b)$ depicts the $\varepsilon_{x x}$ strain mapping of the InGaAs NW/Si heterointerface. 

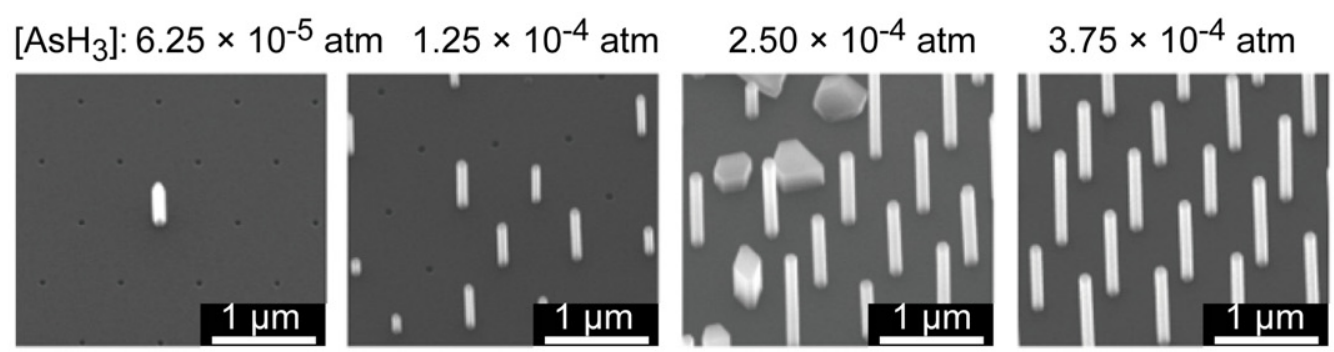

$5.00 \times 10^{-4} \mathrm{~atm}$

Figure 3. $\mathrm{AsH}_{3}$ partial pressure ([AsH $\left.\mathrm{As}_{3}\right]$ ) dependence of selective-area growth of $\mathrm{InGaAs} \mathrm{NWs}$ on $\mathrm{Si}$.

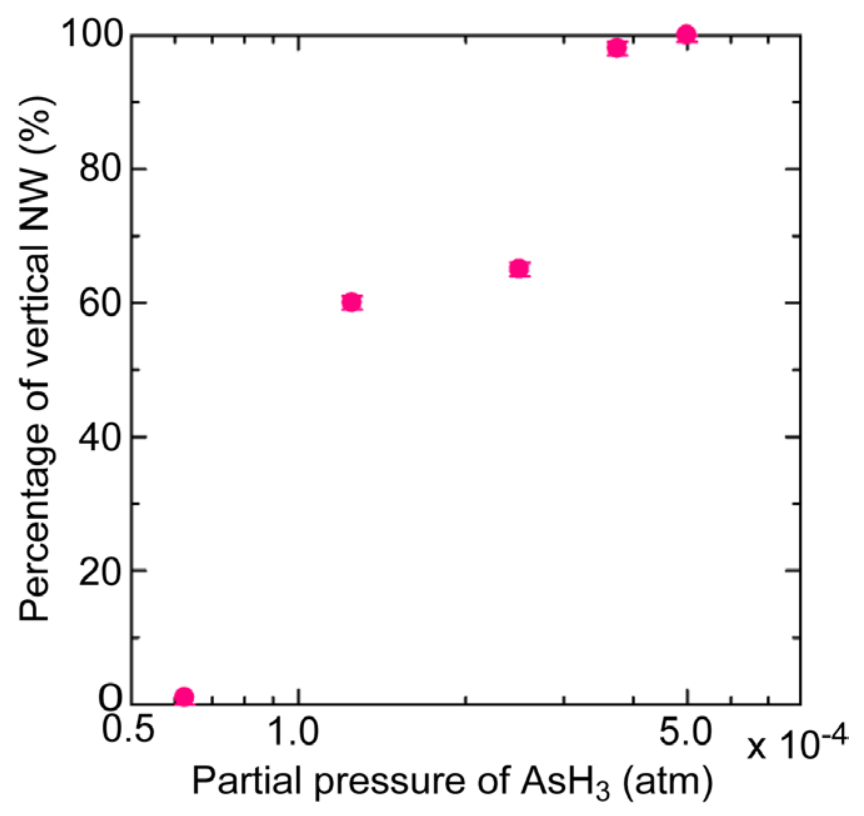

Figure 4. Percentage of vertical InGaAs NWs with variation of $\left[\mathrm{AsH}_{3}\right]$.

The $x x$ direction corresponds to the $\langle-112\rangle$ direction. The strain was calculated by using the peak-pair finding method [134]. The InGaAs NW/Si heterointerface had periodical misfit dislocations. The periodicity of the misfit dislocations was $41.3 \pm 3 \AA$, which coincide with the calculated values from the lattice mismatch (43.1 $\AA$ ). The number of dislocations per unit length is possibly decreased as the $d_{0}$ decreases. The $d_{0}$ dependence of the numbers of misfit dislocations across the III-V NWs/Si heterointerface has been investigated. The results showed that the number of misfit dislocations in the grown III-V NW/Si heterointerface falls appreciably below the calculated numbers from their lattice mismatch as diameter decreases [130]. This helped to predict that coherent growth can be achieved even in highly lattice mismatched systems for smaller diameter with selective-area growth. In fact, coherent growth has been achieved in GaAs NW/Si regardless of the misfit dislocations for $d_{0}=19 \mathrm{~nm}$ [132].

\section{Applications of vertical surrounding-gate FETs using III-V NWs on Si}

Once vertical III-V NWs can be integrated on a $\mathrm{Si}$ substrate using selective-area growth with lithography defined positioning, the grown III-V NWs can be directly be used as III-V channels for vertical surrounding-gate FETs [135]. Si-based CMOS technologies have recently been used to consider the possibility of creating surrounding-gate or gateall-around structures to suppress the off-state leakage current and the III-V materials as alternative channel materials against the strained SiGe channels. These are needed to decrease the power consumption of electronic circuits by decreasing the offstate leakage current and enhancing the on-state current under low bias conditions. Furthermore, the vertical FET structures are expected as building blocks for future three-dimensional large-scale integrated circuit (LSI) chips [136]. Thus, the possibility of using vertical III-V NW channels as alternative channels on Si platforms has attracted a great deal of attention. In addition, these III-V NW channels grown by using selectivearea growth would be used for high-performance back-endon-line (BEOL) transistors as well as for front-end-on-line (FEOL) transistors such as Si-CMOS technologies.

A vertical FET using compound semiconductor NWs was firstly reported by $\mathrm{Ng}$ et al in 2004 [137]. As for As/P-related III-V NWs, VLS grown InAs NWs on InAs substrates were first studied for vertical FET applications [138] and InAs NWs wrapped-gate transistors were demonstrated on Si substrates [10]. Vertical surrounding-gate FETs using InAs NWs on $\mathrm{Si}$, which are grown by using the selective-area method, have also been demonstrated [11]. In addition, InGaAs NW channels grown by using selective-area growth were recently achieved on $\mathrm{Si}$ substrates $[13,75]$.

The details of the device processes for these vertical surrounding-gate FET structures were previously reported $[11,13,75]$. We used a spin-coated low-dielectric insulating layer to isolate the source/gate/drain electrodes and an etchback process using reactive-ion etching (RIE) to fabricate vertical surrounding-gate architecture. Figure 6 summarizes the recent progress made with vertical surrounding-gate FETs using InGaAs NW channels on Si [13, 75, 139]. The device had ten NWs connected in parallel with the drain metal. The measured current was divided by the number of NWs, and the current per NW was normalized by the outer perimeter of the gate metal. Table 1 summarizes the device parameters and performances for each device in figures $6(a)-(c)$. In figure 6(a), we first demonstrate characteristics of InGaAs NW FETs that were all doped by $\mathrm{Si}$ with a carrier concentration $(n)$ of approximately $1 \times 10^{18} \mathrm{~cm}^{-3}$ [13], which is similar to the junction-less transistor [140]. The threshold voltage $\left(V_{\mathrm{T}}\right)$ in this vertical FET was $-0.37 \mathrm{~V}$ and the drain current $\left(I_{\mathrm{D}}\right)$ was modulated by the gate voltage $\left(V_{\mathrm{G}}\right)$ with a subthreshold slope 

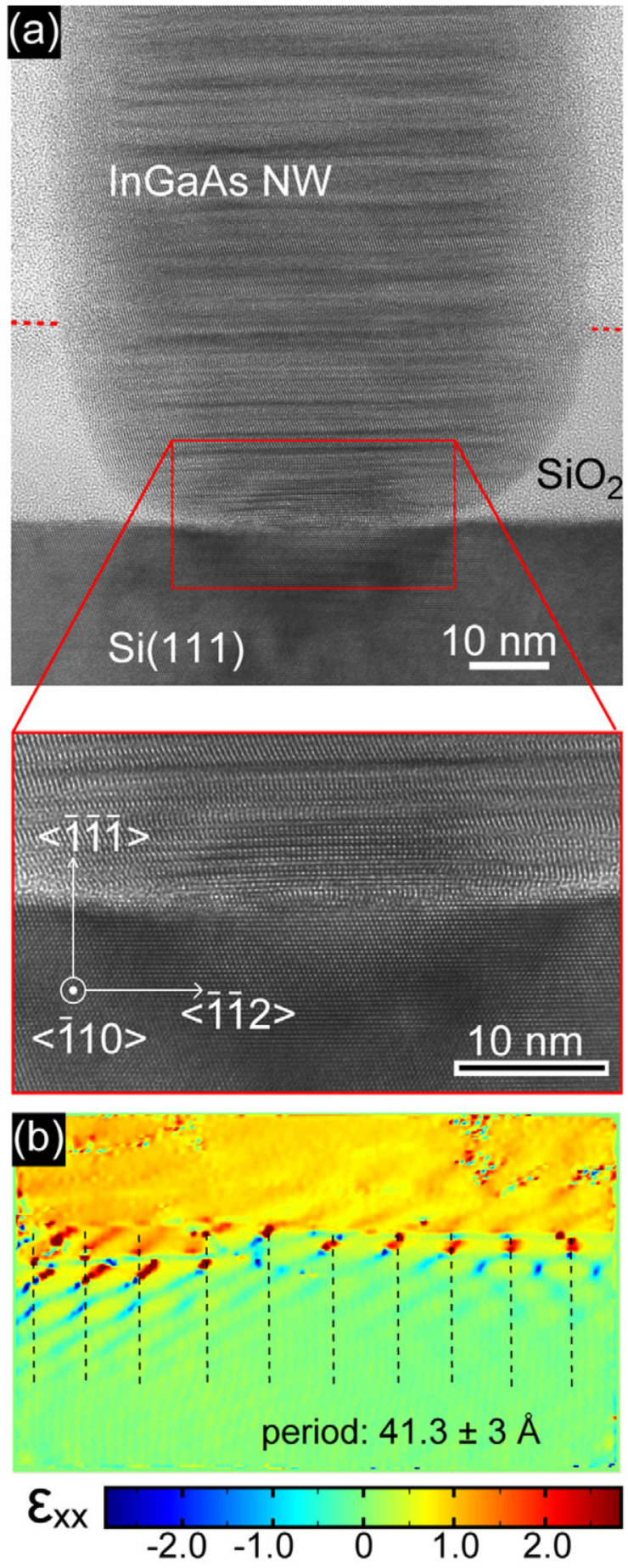

Figure 5. (a) TEM image showing InGaAs NW on Si. The NW is $76 \mathrm{~nm}$ in diameter and the heterointerface is $33 \mathrm{~nm}$ in diameter. Magnified TEM image of the red-square panel (bottom). (b) $\varepsilon_{x x}$ strain mapping calculated from the red square in $(a)$. The dashed lines denote the positions of misfit dislocations.

(SS) of $98 \mathrm{mV} /$ decade. The drain-induced-barrier lowering (DIBL) was $165 \mathrm{mV} / \mathrm{V}$. Next, the InGaAs NW channel was improved in figure $6(b)$. In this case, the InGaAs NW comprises Si-doped InGaAs $\left(1 \times 10^{18} \mathrm{~cm}^{-3}\right)$ stacked on undoped InGaAs $\left(5 \times 10^{16} \mathrm{~cm}^{-3}\right)$ and had a diameter of $60 \mathrm{~nm}$ [75]. The $V_{\mathrm{T}}$ of the FET shifts to positive to $0.18 \mathrm{~V}$ due to the reduction of $n$ in the NW-channel region and improves the SS by decreasing the NW capacitance. Then, $V_{\mathrm{T}}$ was shifted to $0.18 \mathrm{~V}$. The SS and DIBL were improved to $85 \mathrm{mV} /$ decade and $48 \mathrm{mV} / \mathrm{V}$. Next we optimized the EOT of the InGaAs vertical surrounding-gate FET in figure $6(c)$. In this device, the oxide thickness was $4 \mathrm{~nm}$ and effect-oxide thickness estimated from the dielectrics was $0.75 \mathrm{~nm}$. We introduced a gate-metal etching process to avoid as much process damage to the gate oxide as possible [139]. Eventually, we achieved moderate switching properties with an SS of $68 \mathrm{mV} /$ decade and a DIBL of $33 \mathrm{mV} / \mathrm{V}$. Through a series of device advances, the quality of the InGaAs/HfAlO interface was improved and the interface state density $\left(D_{\mathrm{it}}\right)$ ranged from 1.8 to $3.8 \times 10^{12} \mathrm{~cm}^{-2} \mathrm{eV}^{-1}$ with an EOT variation, and the $I_{\mathrm{D}}$

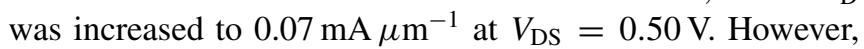
the $I_{\mathrm{D}}$ for the InGaAs vertical surrounding-gate FETs was much lower than that of a Si-MOSFET. Moreover, further advanced techniques are required for higher $I_{\mathrm{D}}$ because future low operation power (LOP) devices that will be required in

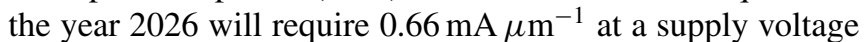
of $0.54 \mathrm{~V}$ [141]. Thus, we need novel techniques such as passivation and ballistic transport for the InGaAs vertical surrounding-gate FET in order to enhance the $I_{\mathrm{D}}$ at a lower supply voltage.

We designed the InGaAs-InP-InAlAs-InGaAs coremultishell (CMS) NW [14,75] shown in figure 7(a). The InAlAs consisted of InAlAs/Si-doped InAlAs/InAlAs modulation-doped multi-layers and forms two-dimensional electron gas (2DEG) inside the core InGaAs NW under a positive $V_{\mathrm{G}}$. Although the InAlAs shell layer without a modulation-doped layer was confirmed to have a passivation effect, the $I_{\mathrm{D}}$ and $G_{\mathrm{m}}$ were not markedly enhanced as compared to that of a bare-InGaAs NW channel. The 2DEG of the CMS NW enhances the $I_{\mathrm{D}}$ at a lower supply voltage. Figures $7(b)$ $(g)$ shows summaries of cross-section TEM images and the transfer characteristics of the vertical surrounding-gate FET of the CMS NWs $[14,75,139]$. For the thicker shell layer in figure $7(b)$, the SS was as large as $130 \mathrm{mV} /$ decade, and the transfer curve in figure $7(c)$ showed kinks at around $V_{\mathrm{G}}=$ $-0.50 \mathrm{~V}$, which were caused by the thickness fluctuation of the outer InGaAs shell layers in figure $7(b)$. The thickness fluctuation was caused by a slight difference in the nucleation process of the InGaAs on the InAlAs surface. The $V_{\mathrm{T}}$ was $-0.07 \mathrm{~V}$. The thickness for thin CMS layers was uniform and the SS was improved to $75 \mathrm{mV} /$ decade, which is close to that of the bare InGaAs NW vertical surrounding-gate FET.

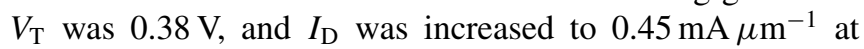
$V_{\mathrm{DS}}=V_{\mathrm{G}}-V_{\mathrm{T}}=0.50 \mathrm{~V}$ [75]. The SS for the InGaAs CMS $\mathrm{NW}$ became $70 \mathrm{mV} /$ decade by further decreasing the thickness of the outer InGaAs layer in figures $7(f)$ and $(g)$. The $I_{\mathrm{D}}$ was slightly decreased to $0.43 \mathrm{mS} \mu \mathrm{m}^{-1}$ at $V_{\mathrm{DS}}=V_{\mathrm{G}}-V_{\mathrm{T}}=$ $0.50 \mathrm{~V}$, which resulted from the increases in the InP and InAlAs thickness. The important point regarding the CMS NW is that $\mathrm{Al}$ segregation occurs at the corner of the CMS, which forms an Al-rich InAlAs layer and divides the radial HEMT layer into a six-sided HEMT layer. This helped to integrate six HEMTs on a single InGaAs NW.

Next, we characterized the oxide-thickness dependence of the vertical surrounding-gate FET using InGaAs CMS NWs. 

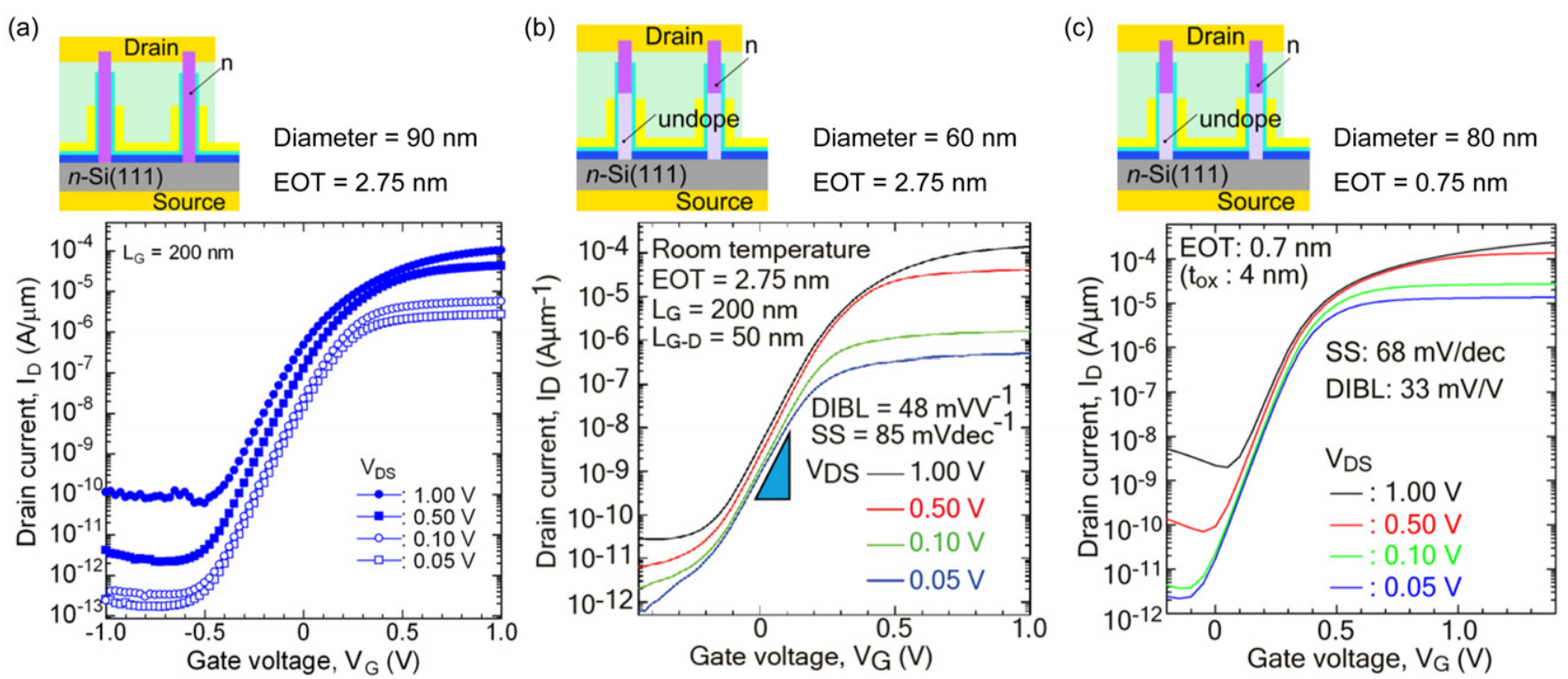

Figure 6. Transfer curves for surrounding-gate FETs using InGaAs NW channels: (a) Si-doped InGaAs NW channel (adapted with permission from [13], Copyright 2011 IEEE), (b) Si-doped InGaAs/undoped InGaAs axial NW channel (adapted with permission from [75], Copyright 2012 Nature) and (c) Si-doped InGaAs/undoped InGaAs axial NW channel with EOT $=0.75 \mathrm{~nm}$ (adapted with permission from [139], Copyright 2013 IEEE).

Table 1. Summary of device performance in figure 6.

\begin{tabular}{lllllllllll}
\hline Material & Sub. & EOT & $\begin{array}{l}d_{\mathrm{NW}} \\
(\mathrm{nm})\end{array}$ & $\begin{array}{l}L_{\mathrm{G}} \\
(\mu \mathrm{m})\end{array}$ & $\begin{array}{l}I_{\mathrm{DS}}\left(\mathrm{mA} \mu \mathrm{m}^{-1}\right) \\
\text { at } V_{\mathrm{DS}}=1.00 \mathrm{~V}\end{array}$ & $\begin{array}{l}I_{\mathrm{DS}}\left(\mathrm{mA} \mu \mathrm{m}^{-1}\right) \\
\text { at } V_{\mathrm{DS}}=0.50 \mathrm{~V}\end{array}$ & $\begin{array}{l}I_{\text {off }}\left(\mathrm{nA} \mu \mathrm{m}^{-1}\right) \\
\text { at } V_{\mathrm{DS}}=0.50 \mathrm{~V}\end{array}$ & $\begin{array}{l}I_{\mathrm{on}} / I_{\text {off }} \\
\text { at } V_{\mathrm{DS}}=0.50 \mathrm{~V}\end{array}$ & $\begin{array}{l}\mathrm{SS} \\
(\mathrm{mV} / \mathrm{dec})\end{array}$ & $\begin{array}{l}\mathrm{DIBL} \\
(\mathrm{mV} / \mathrm{V})\end{array}$ \\
\hline Figure 6 $(a)$ & $\mathrm{Si}$ & 2.75 & 90 & 0.20 & 0.16 & 0.02 & $10^{-3}$ & $10^{7}$ & 97 & 160 \\
Figure 6 $(b)$ & $\mathrm{Si}$ & 2.75 & 60 & 0.15 & 0.25 & 0.04 & $10^{-2}$ & $10^{6}$ & 85 \\
Figure 6(c) & $\mathrm{Si}$ & 0.75 & 80 & 0.15 & 0.21 & 0.07 & $10^{-1}$ & $10^{6}$ & 68 & 33 \\
\hline
\end{tabular}

Figure $8(a)$ depicts the transfer curves at $V_{\mathrm{DS}}=0.50 \mathrm{~V}$ with EOT variation. In this characterization, the diameter of the NW was fixed to $100 \mathrm{~nm}$ and that of the core-InGaAs NW was fixed to $55 \mathrm{~nm}$. Figure 8(b) shows the EOT dependence of SS and DIBL. We characterized ten devices for each EOT and plotted the averages in figure $8(b)$. The SS and DIBL deceased with decreasing EOT: $70 \pm 3 \mathrm{mV} /$ decade and $24 \pm 4 \mathrm{mV} / \mathrm{V}$ were obtained for EOT $=0.75 \mathrm{~nm}$. On the other hand, $I_{\mathrm{D}}$ was constant with the EOT variation. This was because the carrier density of the 2DEG was not changed by the difference in EOT.

The advantage of using the direct integration of III-V NWs on Si substrates by selective-area growth is that the radial growth mode such as that for the InGaAs-InP-InAlAsInGaAs CMS NW can be distinctly formed around the sidewalls on the NW channel. Moreover, the III-V NW/Si heterojunction forms a large conduction band offset across the III-V NW/Si heterojunction. The band offset is convenient for high mobility channel materials such as InGaAs and InAs, whose channels always lead to a high off-leakage current with a low effective electron mass. In figure $8(a)$, the off-state leakage current was surely reduced to $10 \mathrm{pA} \mu \mathrm{m}^{-1}$, which was three orders of magnitude lower than that of future LOP transistors (the off-state leakage current is $5 \mathrm{nA} \mu \mathrm{m}^{-1}$ ). Instead, these III-V/Si heterojunctions tend to possess higher series resistance. The next challenges for the vertical FETs using III-V NW channels are reduction of resistance and demonstration of p-channel FETs.

\section{Applications of tunnel FETs using III-V/Si heterojunction}

In addition to the simple integration of vertical III-V NW channels on $\mathrm{Si}$, the heterointerface across III-V NW/Si works as a specific tunnel junction when III-V NWs are grown on Si regardless of any defects such as threading dislocations and anti-phase defects. We have proposed the application of tunnel FETs using the III-V/Si heterojunctions [142] shown in figure 9, and first demonstrated the vertical tunnel FET using an InAs NW/Si heterojunction as a n-channel switch shown in figure 9(a) [39]. The big goal for the TFET for application in CMOS technologies is to achieve a steep SS of below $60 \mathrm{mV} /$ decade and increase the tunnelling current. In the n-channel vertical TFET using III-V NW/Si heterojunctions, one must consider the series resistances of the device structure, which are (1) contact resistance, (2) channel resistance, and (3) junction resistance, in order to achieve a steeper SS. This is because the SS in a TFET can be expressed as a function of $V_{D S}$ and $V_{\mathrm{G}}[143]$.

(1) Contact resistance. The contact resistance should be lowered as far as possible because it affects the reverse bias. For steep SS switching, the reverse bias should be higher under a small $V_{\mathrm{DS}}$. It is very difficult to decrease the contact resistance for a III-V NW with a small diameter. Thus, enlargement of the contact area was effective for reducing the series resistance, as mentioned in a previous 
(a)

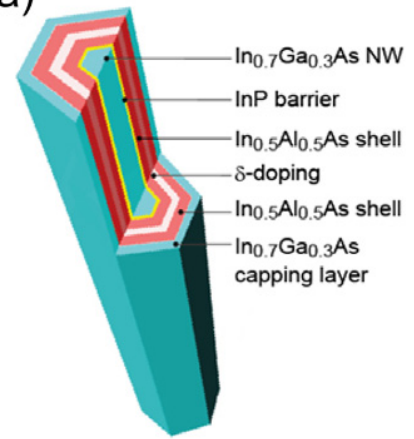

(d)

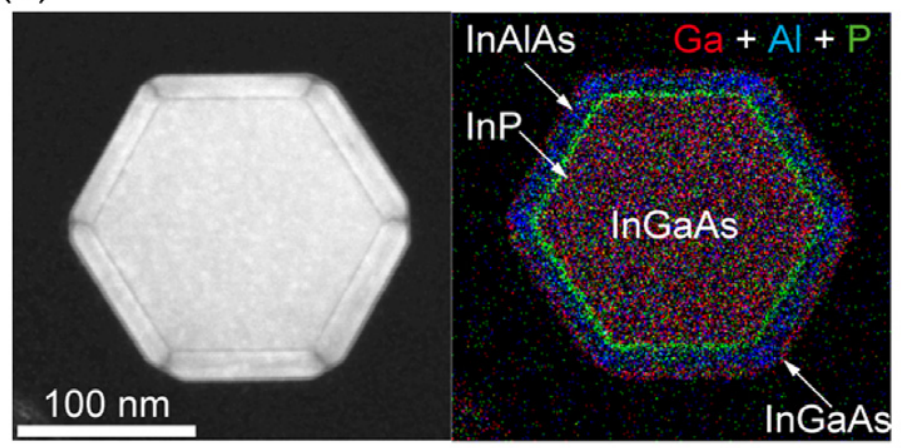

(f)

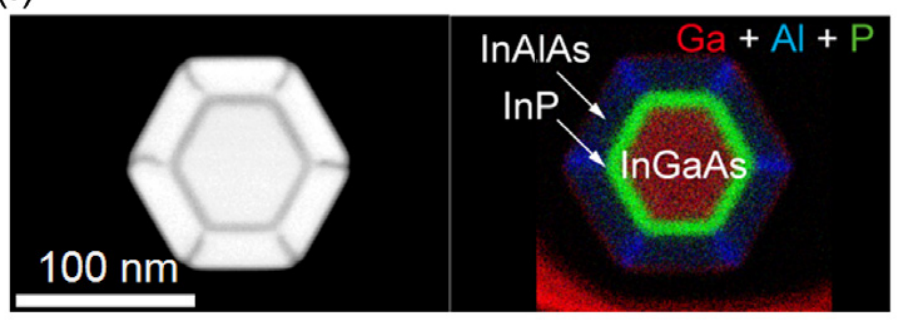

(b)

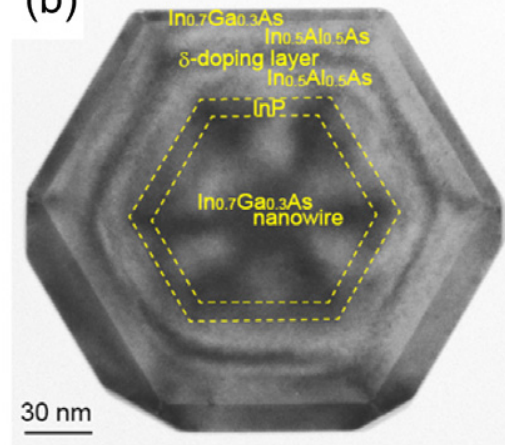

(e)
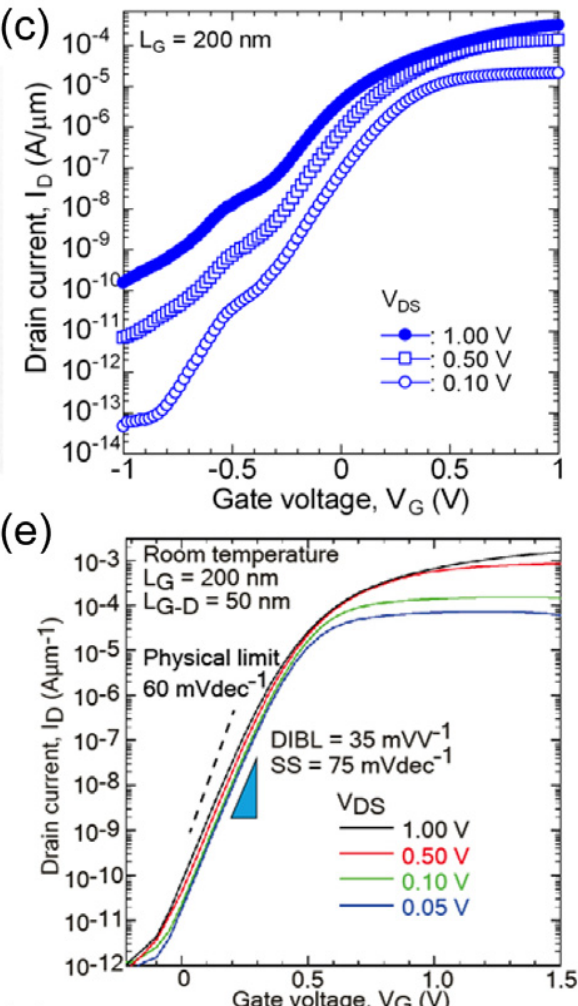

(g)

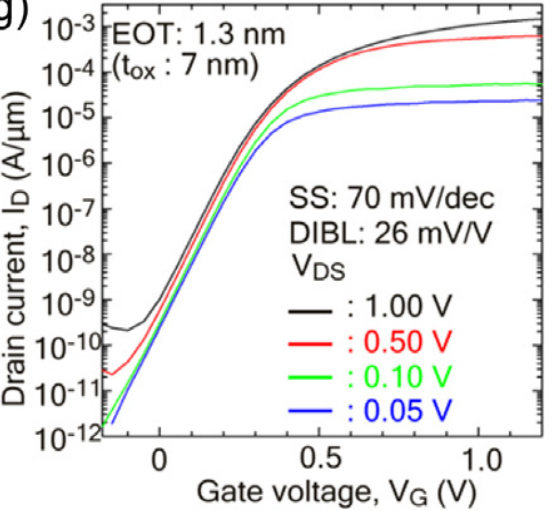

Figure 7. (a) Illustration of InGaAs-InP-InAlAs-InGaAs CMS NW. (b) Cross-section TEM image of CMS NW with thicker shell layers. (c) Transfer curves measured from surrounding-gate FET using the CMS NW in $(b)$. (d) Bright-field scanning TEM (BF-STEM) image and EDX elemental mapping for Ga-Al-P of the CMS NW with thicker shell layers. (e) Transfer curves measured from CMS NW channel in $(d) .(f)$ BF-STEM image and EDX elemental mapping for Ga-Al-P of CMS NW with thinner shell layer. $(g)$ Transfer curves measured from CMS NW channel in $(f)$. (Adapted with permission from [13] Copyright 2011 IEEE, [75], Copyright 2012 Nature [139], Copyright 2013 IEEE).

report [142]. In addition, the formation of a Ni/III-V alloy was effective at reducing the contact resistance [144].

(2) Channel resistance. This resistance should be higher to induce a large internal electrical field. Thus, the formation of intrinsic NWs is important. However, III-V NW channels formed using MOVPE intrinsically contain carbon impurities. For example, InAs has a carrier concentration of $10^{16}-10^{17} \mathrm{~cm}^{-3}$, which results from the carbon impurity from the metal-organic precursor. It is very difficult to reduce the intrinsic carrier concentration in a very small nanostructure, since a single dopant atom provides a high carrier concentration at an order of $10^{17} \mathrm{~cm}^{-3}$ when the diameter of the III-V NW is below $30 \mathrm{~nm}$. We introduced a pulsed-doping technique of p-type impurities during the growth of the III-V NWs to compensate for residual donor impurities, and demonstrated the turn-on voltage shift of TFET using an InAs NW/Si heterojunction by decreasing the intrinsic carrier concentration [130]. In addition, steep SS was achieved in the vertical TFET using an InGaAs NW/Si heterojunction [120].

(3) Junction resistance. The resistance should be the highest among the other series resistances because a higher junction resistance induces a larger internal electrical field under a lower $V_{\mathrm{G}}$ or $V_{\mathrm{DS}}$. However, the III-V/Si heterointerface inherently forms misfit dislocation networks due to the lattice mismatch. The misfit dislocations form defect levels across the III-V/Si 


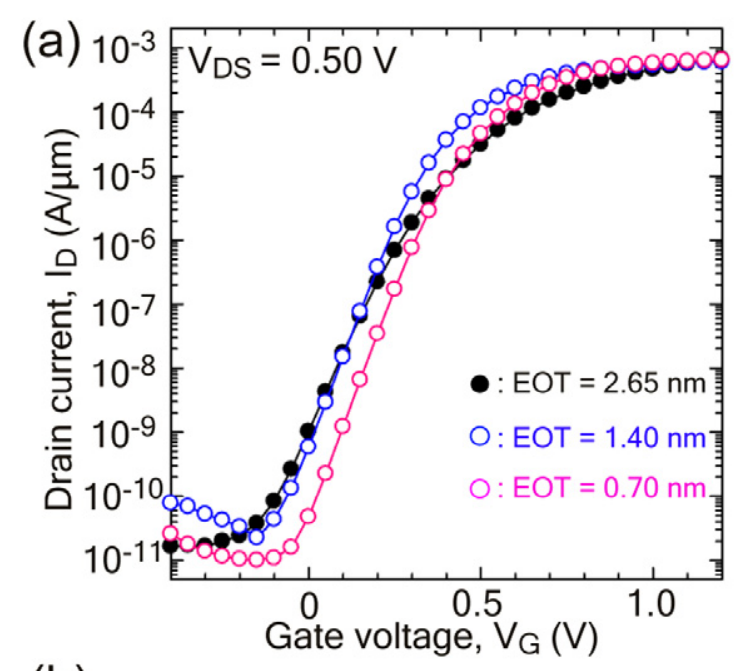

(b)

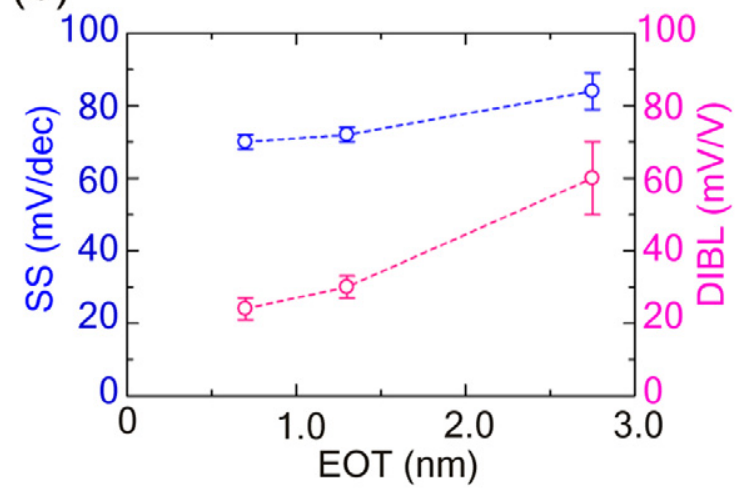

Figure 8. (a) EOT dependence of transfer curve of InGaAs CMS NW channel. $V_{\mathrm{DS}}=0.50 \mathrm{~V}$. (b) Average SS and DIBL of InGaAs CMS NW channel with variation of EOT.

heterojunction and a tunnelling transport process occurs through the defect levels, which is called trap-assisted tunnelling (TAT). When the TAT is the dominating process, the SS increases because the tunnelling leakage current is increased. The heterointerface should possess zero misfit dislocations in order to suppress the TAT process, and thus, coherent growth should be achieved with the integration of III-V NWs on Si. The reduction of the crystal growth area was recently proven effective at reducing the number of misfit dislocations across the III-V NW/Si heterointerface, and report on this also predicted the coherent growth mode was able to be achieved by decreasing the diameter of the openings [130], and reducing the diameter of heterointerface in practical TFETs using InAs NW/Si heterojunctions produced a steep SS turn-on switching with a minimum of $12 \mathrm{mV} /$ decade at room temperature [130, 142].

We have also demonstrated n-channel vertical TFETs with III-V NW/Si heterojunctions. However, p-channel vertical TFETs with InAs NW/Si heterojunctions have been less investigated [68]. In particular, there has been no report regarding a p-channel TFET with p-type III-V NW/n-type $\mathrm{Si}$ heterojunctions like that shown in figure $9(b)$. Here we demonstrate the selective-area growth of p-type InAs NWs on $\mathrm{Si}$ and the fabrication of vertical TFETs with $\mathrm{p}$-InAs/Si heterojunctions as a p-channel switch.

The substrate was n-type $\operatorname{Si}\left(\begin{array}{lll}1 & 1 & 1\end{array}\right)(r=0.1 \Omega \mathrm{cm})$. InAs NWs were grown in a low-pressure horizontal MOVPE system. The growth conditions included a partial pressure of TMIn, [TMIn] $=4.87 \times 10^{-7} \mathrm{~atm}$, a partial pressure of $\mathrm{AsH}_{3}$, $\left[\mathrm{AsH}_{3}\right]=1.25 \times 10^{-4}$ atm, growth temperatures of 540 and $560^{\circ} \mathrm{C}$, and a growth time $=7 \mathrm{~min}$. We used diethylzinc (DEZn) for the p-type doping of the InAs NWs. The growth conditions for controlling the InAs NWs followed those in the previous report [131]. The [DEZn]/[TMIn] ratio was 4.8. The carrier concentration of the planar $\mathrm{p}$-InAs grown under the same conditions was approximately $1 \times 10^{18} \mathrm{~cm}^{-3}$. The diameters of the openings were fixed to $70 \mathrm{~nm}$.

Figure 10(a) shows Zn-doped InAs NWs on a Si substrate grown at $540{ }^{\circ} \mathrm{C}$. The diameter of the grown InAs NWs was about $130 \mathrm{~nm}$, which indicates that the lateral overgrowth along the $\left[\begin{array}{lll}-1 & 1 & 0\end{array}\right]$ directions was enhanced even though there was optimum $T_{\mathrm{G}}$ for the InAs NW growth [145]. The rate of the lateral overgrowth was approximately $4.3 \mathrm{~nm} \mathrm{~min}^{-1}$. The enhancement of the lateral overgrowth using $\mathrm{Zn}$ doping indicates that the nucleation process on the $\{-110\}$ side facets of the InAs NWs was increased. This means that the adsorption processes of the In atoms were enhanced due to the $\mathrm{Zn}$ atoms because the surface diffusion length of the In atoms shortened due to the $\mathrm{Zn}$. Thus, the supersaturation of the In atoms increased on the $\{-110\}$ side facets with the growth of $\mathrm{Zn}$-doped InAs NWs. It should be noted that the desorption process of the As adatoms on the $\{-110\}$ facets was not changed by any dopants. Figure $10(b)$ depicts the Zn-doped InAs NWs grown at $560^{\circ} \mathrm{C}$. The slightly increased $T_{\mathrm{G}}\left(>540^{\circ} \mathrm{C}\right)$ suppressed the lateral overgrowth of the Zn-doped InAs NWs. The lateral overgrowth for the InAs NWs was suppressed under the growth conditions. In this case, the desorption process of the As atoms was enhanced and the adsorption process was decreased under a higher $T_{\mathrm{G}}$.

Next, we formed InAs NWs comprised of a Zn-doped InAs/Zn-pulse doped InAs axial junction. The purpose of the pulsed doping is to create an intrinsic layer by using the compensation effect. After growth of the Zn-pulse doped InAs $\mathrm{NW}$ at $540{ }^{\circ} \mathrm{C}$ for $5 \mathrm{~min}$, the NW growth was resumed at $560^{\circ} \mathrm{C}$ for 10 min using $\mathrm{Zn}$ doping to create pseudo-intrinsic InAs $/ \mathrm{p}^{+}$InAs axial junctions on an $\mathrm{n}-\mathrm{Si}$ substrate. The $\mathrm{NW}$ was $70 \mathrm{~nm}$ in diameter and $1.2 \mu \mathrm{m}$ in height. The device processes for the vertical FET structure were the same as in previous reports [130]. We used a single InAs NW for the device. The gate oxide was $\mathrm{Hf}_{0.8} \mathrm{Al}_{0.2} \mathrm{O}$ with a thickness of $10 \mathrm{~nm}$, and the gate metal was tungsten. The gate length was $150 \mathrm{~nm}$, the drain metal was a Ti-Pt-Au non-alloy Ohmic electrode and the source metal was a $\mathrm{Ni}-\mathrm{Au}$ electrode. After depositions of the source and drain electrodes, the device was annealed at $330{ }^{\circ} \mathrm{C}$ for $5 \mathrm{~min}$ in $\mathrm{N}_{2}$.

Figure 11 shows the transfer curve of the device. The negative $V_{\mathrm{DS}}$ was reverse biased in the direction against the $\mathrm{Zn}$-doped InAs/Zn-pulse doped InAs/n-Si junction because the source electrode was grounded. This curve indicates that the tunnelling current from the n-Si to the InAs NW was modulated by the negative $V_{\mathrm{G}}$, which follows the simulation results in 

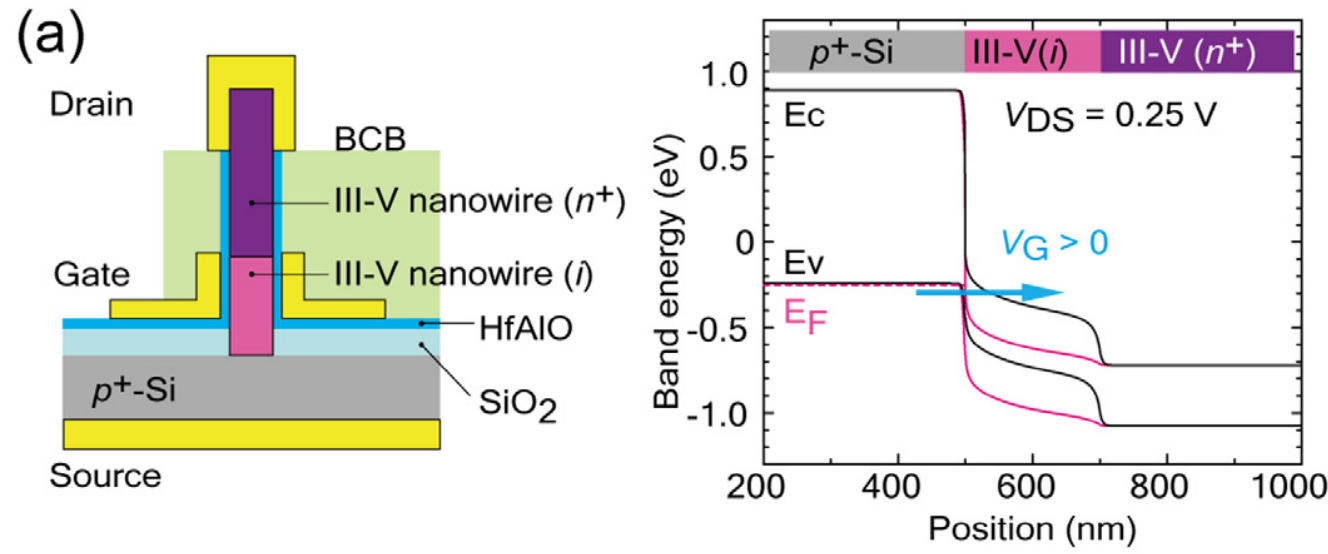

(b)

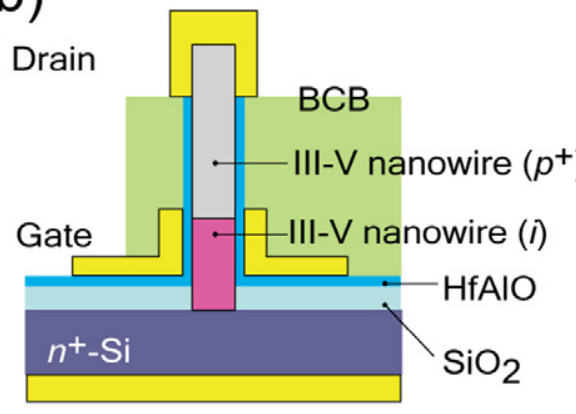

Source

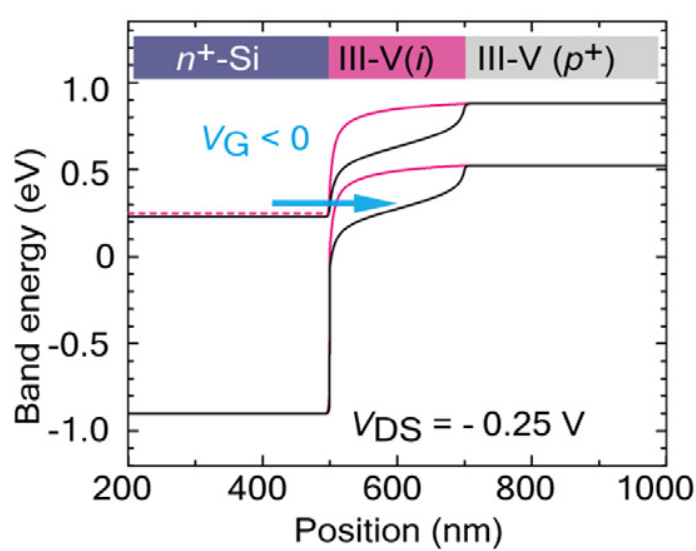

Figure 9. Device designs of vertical TFET using III-V NW/Si heterojunction: (a) n-channel TFET on Si(1 111$)$ using III-V NW to serve as channel and drain and a one-dimensional Poisson-Schrödinger solver. At $V_{\mathrm{DS}}=0.25 \mathrm{~V}$, the positive gate bias (pink curve) induces Zener tunnelling transport from the p-Si to the III-V NWs. $(b)$ p-channel TFET using III-V NW. At $V_{\mathrm{DS}}=-0.25 \mathrm{~V}$, the negative $V_{\mathrm{G}}$ (pink curve) induces Zener tunnelling transport from the $\mathrm{n}-\mathrm{Si}$ to the III-V NW.
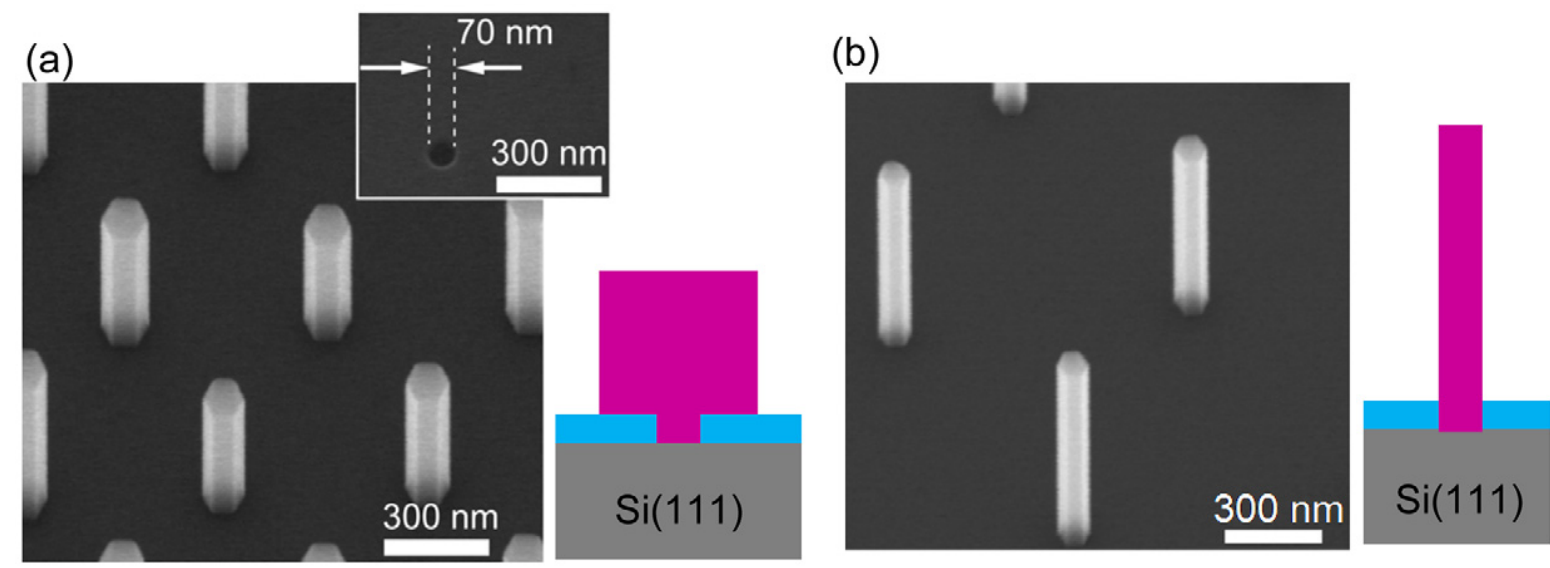

Figure 10. (a) SEM image showing Zn-doped InAs NWs on $\mathrm{Si}(111)$ grown at $540^{\circ} \mathrm{C}$. The inset shows the mask pattern. (b) SEM image showing Zn-doped InAs NWs on $\mathrm{Si}\left(\begin{array}{llll}1 & 1 & 1\end{array}\right)$ grown at $560^{\circ} \mathrm{C}$.

figure $9(b)$. The SS was $86 \mathrm{mV} /$ decade at $V_{\mathrm{DS}}=-0.25 \mathrm{~V}$. $I_{\text {on }} / I_{\text {off }}$ was about $10^{4}$ at $V_{\mathrm{DS}}=-0.25 \mathrm{~V}$. $I_{\text {off }}$ was increased with increasing $V_{\mathrm{DS}}$, and $I_{\mathrm{on}} / I_{\mathrm{off}}$ decreased. This was because the Fermi level in the n-Si started to overlap that of the InAs due to the increase in $V_{\mathrm{G}}$ at a low $V_{\mathrm{DS}}$. In this case, the tunnelling current is moderately modulated by $V_{\mathrm{G}}$ and the switching behaviour appeared, while at a high $V_{\mathrm{DS}}$ the Fermi level in the n-Si overlapped that of the InAs, and then the tunnel current itself could be the leakage current. This resulted from the $\mathrm{Zn}$ interdiffusion that occurred from the $\mathrm{Zn}$-doped InAs to $\mathrm{Zn}$-pulse doped InAs channel region during the $\mathrm{Zn}$-doped InAs NW growth, and the channel region became p-type InAs. Thus, voltage overlapping occurred in the InAs channel and drain regions under negative $V_{\mathrm{DS}}$. This voltage overlapping due to the interdiffusion also degraded the SS, and thus a steeper SS below $60 \mathrm{mV} /$ decade was not achieved in this case. 


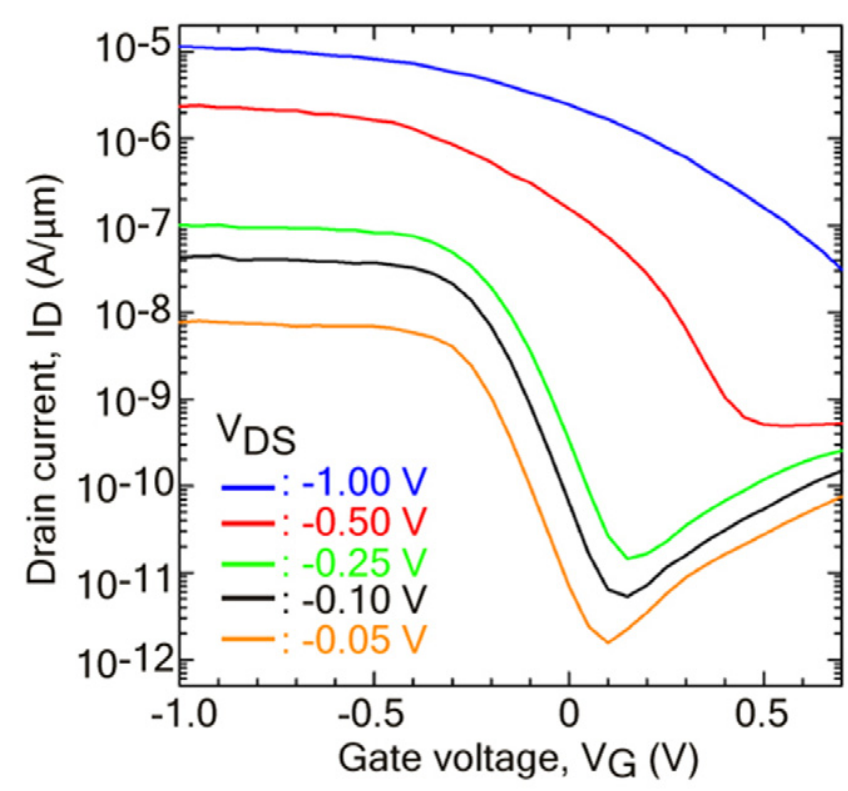

Figure 11. Transfer curve of p-channel TFET using Zn-doped InAs/Zn-pulse doped InAs/n-Si heterojunction at room temperature.

Although the device currently has degradation in the SS at $V_{\mathrm{DS}}>-0.50 \mathrm{~V}$, the device is an attractive possibility for higher $I_{\mathrm{on}}$ current in the tunnel transport regime. $I_{\mathrm{on}}$ was $2 \mu \mathrm{A} \mu \mathrm{m}^{-1}$ at $V_{\mathrm{DS}}=V_{\mathrm{G}}=-0.50 \mathrm{~V}$, which is higher than that of a p-channel TFET using a III-V/Si heterojunction [68]. Further optimization of the device structure may be necessary to achieve both a high $I_{\text {on }}$ and steep SS turn-on properties.

\section{Summary}

We have reviewed the recent progresses made with vertical III-V NWs, specifically the InGaAs and Zn-doped InAs NWs, on Si substrates by using selective-area growth. We also discussed vertical surrounding-gate transistors using III-V NW channels on $\mathrm{Si}$ as a first step towards attaining future vertical systems or integrating chips. The use of modulation-doped CMS NWs enhanced the performance of InGaAs NW-based surrounding-gate FETs on Si while maintaining an SS of $70 \mathrm{mV} /$ decade. Finally, we reviewed the recent achievements made using TFETs with III-V NW/Si heterojunctions and discussed the application for $\mathrm{p}$-channel TFETs by using Zn-doped InAs NW/Si heterojunctions for the first time. Our next target is to integrate these highperformance III-V NW surrounding-gate FETs and TFETs based on the III-V NW/Si junctions into a Si-LSI platform and to build low power electronic circuits.

\section{Acknowledgments}

The authors would like to thank Professors Junichi Motohisa and Tamotsu Hashizume for fruitful discussions. We especially thank $\mathrm{Dr} M$ Yoshimura, Mr E Nakai, and Mr F Ishizaka for supporting MOVPE growths. This work was financially supported by a Grant-in-Aid for Scientific Research from the Ministry of Education, Culture, Sports, Science and
Technology (MEXT) and the Japan Science and Technology Agency (JST) PRESTO programme.

\section{References}

[1] Huang Y, Duan X, Cui Y, Lauhon L J, Kim K-H and Lieber C M 2001 Science 2941313

[2] Huang M H, Mao S, Feick H, Yan H, Wu Y, Kind H, Weber E, Russo R and Yang P 2001 Science 2921897

[3] Gudiksen M S, Lauhon L J, Wang J, Smith D C and Lieber C M 2002 Nature 415617

[4] Lauhon L J, Gudiksen M S, Wang D and Lieber CM 2002 Nature 42057

[5] Johnson J C, Choi H-J, Knutsen K P, Schaller R D, Yang P and Saykally R J 2002 Nature Mater. 1106

[6] Hiruma K, Yazawa M, Katsuyama T, Ogawa K, Haraguchi K, Koguchi M and Kakibayashi H 1995 J. Appl. Phys. 77447

[7] del Alamo J A 2011 Nature 479310

[8] Radosavljevic M et al 2009 IEEE IEDM Technical Digest pp 319

[9] Kim S H et al 2012 Appl. Phys. Exp. 5014201

[10] Rehnstedt C et al 2008 IEEE Trans. Electron Devices 553037

[11] Tanaka T, Tomioka K, Hara S, Motohisa J, Sano E and Fukui T 2010 Appl. Phys. Exp. 3025003

[12] Wernersson L-E, Thelander C, Lind E and Samuelson L 2010 Proc. IEEE 982047

[13] Tomioka K, Yoshimura M and Fukui T 2011 IEEE IEDM Technical Digest 773

[14] Gorji Ghalamestani S, Johansson S, Borg M, Lind E, Dick K A and Wernersson L E 2012 Nanotechnology 23015302

[15] Johansson S, Egard M, Gorji Ghalamestani S, Borg M, Berg M, Wernesson L E and Lind E 2011 IEEE Trans. Micro. Theory Tech. $\mathbf{5 9} 2733$

[16] Wagner R S and Ellis W C 1964 Appl. Phys. Lett. 489

[17] Fontucuberta i Morral A, Colombo C, Abstreiter G, Arbiol J and Morante J R 2008 Appl. Phys. Lett. 92063112

[18] Tomioka K, Ikejiri K, Tanaka T, Motohisa J, Hara S, Hiruma K and Fukui T 2011 J. Mater. Res. 142127

[19] Mårttensson T, Patrik C, Svensson T, Wacasar B A, Larsson M W, Seifert W, Deppert K, Gustafsson A, Wallenberg L R and Samuelson L 2004 Nano Lett. 41987

[20] Tomioka K, Tanaka T, Shijiro H, Hiruma K and Fukui T 2011 IEEE J. Sel. Top. Quantum Electron. 171112

[21] Krongstrup P, Popovitz-Biro R, Jhonson E, Madsen M H, Nygård J and Shtrikman H 2010 Nano Lett. 104475

[22] Plissard S, Dick K A, Larrieu G, Godey S, Addad A, Wallart X and Caroff P 2010 Nanotechnology 21385602

[23] Cirlin G E, Duvrovskii V G, Samsonenko Y B, Bouravleuv A D, Durose K, Proskuryakov Y Y, Mendes B, Bowen L, Kaliteevski M A, Abram R A and Zeze D 2010 Phys. Rev. B 82035302

[24] Breuer S, Hilse M, Trampert A, Geelhaar L and Riechert H 2010 Phys. Rev. B 82075406

[25] Björk M T, Schmid H, Bessire C D, Moselund K E, Ghoneim H, Karg S, Lörtscher E and Riel H 2010 Appl. Phys. Lett. 97163501

[26] Hertenberger S, Rudolph D, Bichler M, Finley J J, Abstreiter G and Koblmüller G 2010 J. Appl. Phys. 108114316

[27] Mandl B, Stangl J, Hilner E, Zakharov A A, Hillerich K, Dey A W, Samuelson L, Bauer G, Deppert K and Mikkelsen A 2010 Nano Lett. 104443

[28] Tatebayashi J, Lin A, Wong P S, Hick R F and Huffaker D L 2010 J. Appl. Phys. 108034315

[29] Dubrovskii V G, Nazarenko M V, Chuang L C, Ko W S, Ng K W and Chang-Hasnain C 2011 Appl. Phys. Lett. 98153113

[30] Kang J-H et al 2011 Cryst Growth Des. 113109 
[31] Miccoli I, Prete P, Marzo F, Cannoletta D and Lovergine N 2011 Cryst. Res. Technol. 46795

[32] Fontcuberta I and Morral A 2011 IEEE J Sel. Top. Quantum Electron. 17819

[33] Suzuki A, Mori T, Fukuyama A, Ikari T, Paek J-H and Yamaguchi M 2011 Japan. J. Appl. Phys. 50 06GH08

[34] Chuang L C, Sedgwick F G, Chen R, Ko W S, Moewe M, Ng K W, Tran T-T D and Chang-Hasnain C 2011 Nano Lett. 11385

[35] Dubrovskii V G, Cirlin G E, Sibirev N V, Jabeen F, Harmand J C and Werner P 2011 Nano Lett. 111247

[36] Uccelli E et al 2011 Nano Lett. 113827

[37] Rudolph D, Hertenberger S, Bolte S, Paosangthong W, Spirkoska D, Döblinger M, Bichler M, Finley J J, Abstreiter G and Koblmüller G 2011 Nano Lett. 113848

[38] Plissard S, Larreieu G, Wallart X and Caroff P 2011 Nanotechnology 22275602

[39] Tomioka K and Fukui T 2011 Appl. Phys. Lett. 98083114

[40] Dimakis E, Lähnemann J, Jahn W, Breuer S, Hilse M, Geelhaar L and Riechert H 2011 Cryst. Growth Des. 114001

[41] Mandl B, Dey A W, Stangl J, Cantoro M, Wernersson L-E, Bauer G, Samuelson L, Deppert K and Thelander C $2011 \mathrm{~J}$. Cryst. Growth 33451

[42] Bessire C D, Björk M T, Schimid H, Schenk A, Reuter K B and Riel H 2011 Nano Lett. 114195

[43] Madsen M H, Aagesen M, Krogstrup P, Sørensen C and Nygård J 2011 Nanoscale Res. Lett. 6516

[44] Li T, Chen Y, Lei W, Zhou X, Luo S, Hu Y, Wang L, Yang T and Wang Z 2011 Nanoscale Res. Lett. 6463

[45] Hörmann N G, Zardo I, Hertenberger S, Funk S, Botle S, Döblinger M, Koblmüller G and Abstreiter G 2011 Phys. Rev. B 84155301

[46] Cantoro M et al 2011 Phys. Status Solidi a 208129

[47] Tomioka K, Tanaka T and Fukui T 2011 ECS Trans. 4161

[48] Shin J C, Kim K H, Yu K J, Hu H, Yin L, Ning C-Z, Roger J A, Zuo J-M and Li X 2011 Nano Lett. 114831

[49] Borgström M T, Wallentin J, Heurlin M, Fält S, Wickert P, Leene J, Magnusson M H, Deppert K and Samuelson L 2011 IEEE J. Sel. Top. Quantum Electron. 171050

[50] Lohn A J, Li X and Kobayashi N P 2011 J. Cryst. Growth 315157

[51] Heurlin M, Wickert P, Fält S, Borgström M T, Deppert K, Samuelson L and Magnusson M H 2011 Nano Lett. 112028

[52] Hadj Alouane M H, Anufriev R, Chauvin N, Khmissi H, Naji $\mathrm{K}$, Ilahi B, Maaref H, Patriarche G, Gendry M and Bru-Chevallier C 2011 Nanotechnology 22405702

[53] Kim Y H, park D W and Lee S J 2012 Appl. Phys. Lett. 100033117

[54] Kim Y H, Park D W, Lee S J, Kim KM and Park Y C 2012 Appl. Phys. Lett. 100133112

[55] Convertino A, Cuscunà M, Rubini S and Mertelli F 2012 Appl. Phys. Lett. 111114302

[56] Chang C-C et al 2012 Nano Lett. 124484

[57] Couto Jr O D D et al 2012 Nano Lett. 125296

[58] Dimakis E, Ramsteiner M, Tahroui A, Riechert H and Geelhaar L 2012 Nano Res. 5796

[59] Yamaguchi M, Paek J-H and Amano H 2012 Nanoscale Res. Lett. 7558

[60] Russo-Averchi E, Heiss M, Michelet L, Krogstrup P, Nygard J, Magen C, Morante J R, Uccelli E, Arbiol J and Fontcuberta i Morral A 2012 Nanoscale 41486

[61] Biermanns A, Breuer S, Trampert A, Davydok A, Gellhaar L and Pietsch U 2012 Nanotechnology 23305703

[62] Kang J H, Gao Q, Parkinson P, Joyce H J, Tan H H, Kim Y, Guo Y, Xu H, Zou J and Jagadish C 2012 Nanotechnology 23415702

[63] Kuang Y J, Sukrittanon S, Li H and Tu C W 2012 Appl. Phys. Lett. 100053108
[64] Dobrovolsky A, Stehr J E, Chen S L, Kuang Y J, Sukrittanon S, Tu C W, Chen W M and Buyanova I A 2012 Appl. Phys. Lett 101163106

[65] Novak J, Šoltýs J, Eliáš P, Hasenöhrl S, Stokalas R, Dujavová A and Mukulics M 2012 Phys. Satus Solidi a 2092505

[66] Zhang Z, Senz S, Zhao F, Chen L, Gao X and Liu J-M 2012 RSC Adv. 28631

[67] Boukanger J P and LaPierre R R 2012 Semicond. Sci. Technol. 27035002

[68] Moselund K E, Schmid H, Bessire C, Björk M T, Ghoneim H and Riel H 2012 IEEE Electron Device Lett. 331453

[69] Björk M T, Schmid H, Breslin C M, Gignac L and Riel H 2012 J. Cryst. Growth 34431

[70] Tian Y, Sakr M R, Kinder J M, Liang D, MacDonald M J, Qin E L J, Gao H-J and Gao P A 2012 Nano Lett. 126492

[71] Shin j C, Mohseni P K, Yu K J, Tomasulo S, Montgomery K H, Lee M L, Rogers J A and Li X 2012 ACS Nano 611074

[72] Hertenberger S et al 2012 Appl. Phys. Lett. 101043116

[73] Yang T, Hertenberger S, Morkötter S, Abstreiter G and Koblmüller G 2012 Appl. Phys. Lett. 101233102

[74] Shin J C, Choi K J, Kim D Y, Choi W J and Li X 2012 Cryst. Growth Des. 122994

[75] Tomioka K, Yoshimura M and Fukui T 2012 Nature 488189

[76] Chauvin N, Hadj Alouane M H, Anufriev R, Khmissi H, Naji K, Patriarche G, Bru-Chevallier C and Gendry M 2012 Appl. Phys. Lett. 100011906

[77] Naji K, Dumont H, Saint-Girons G, Penuelas J, Patriarche G, Hocevar M, Zwiller V and Gendry M 2012 J. Cryst. Growth 343101

[78] Khmissi H, Naji K, Hadj Alouane M H, Chauvin N, Bru-Chevallier C, Ilahi B, Patriarche G and Gendry M 2012 J. Cryst. Growth 34445

[79] Penuelas J, Lu X, Blanchard N P, Saint-Girons G, Vilquin B and Crèmillieu P 2012 J. Cryst. Growth 34749

[80] Miao G and Zhang D 2012 Nanoscale Res. Lett. 7321

[81] Tchernycheva M et al 2012 Nanotechnology 23265402

[82] Casadei A, Krogstrup P, Heiss M, Röhr J A, Colombo C, Ruelle T, Upadhyay S, Søresen C B, Nygård J and Fontcuberta i Morral A 2013 Appl. Phys. Lett. 102013117

[83] Ibanes J J, Balgos M H, Jaculbia R, Salvador A, Somintac A, Estacio E, Que C T, Tsuzuki S, Yamamoto K and Tani M 2013 Appl. Phys. Lett. 102063101

[84] Hu S, Chi C-Y, Fountaine k T, Yao M, Atwater H A, Dapkus P D, Lewis N S and Zhou C 2013 Energy Env. Sci. 61879

[85] Munshi A M, Dheeraj D L, Todorovic J, T. J. van Helvoot A, Weman H and Fimland B-O 2013 J. Cryst. Growth 372163

[86] Kwoen J, Watanabe K, Iwamoto S and Arakawa Y $2013 \mathrm{~J}$. Cryst. Growth 378562

[87] Yan X, Zhang X, Li J, Cui J, Wang Q, Huang Y and Ren X 2013 J. Cryst. Growth 38482

[88] Yu Y et al 2013 Nano Lett. 131399

[89] Rudolph D et al 2013Nano Lett. 131522

[90] Cohin Y, Manguin O, Largeau L, Patriarche G, Glas F, Søndergård E and Harmand J-C 2013 Nano Lett. 132743

[91] Somaschini C, Bietti S, Trampert A, Jahn U, Hauswald C, Riechert H, Sanguinetti S and Geelhaar L 2013 Nano Lett. 133607

[92] Chen G, Sun G, Ding Y J, Prete P, Miccoli I, Lovergine N, Shtrikman H, Kung P, Livneh T and Spanier J E 2013 Nano Lett. 134152

[93] Gas K, Sadowski J, Kasama T, Siusys A, Zaleszczyk W, Wojciechowski T, Morhange J-F, Altintas A, Xu H Q and Szuszkiewicz W 2013 Nanoscale 57410

[94] Araki Y, Yamaguchi M and Ishikawa F 2013 Nanotechnology 24065601

[95] Ikejiri K, Ishizaka F, Tomioka K and Fukui T 2013 Nanotechnology 24115304

[96] Heiss M et al 2013 Nature Mater. 12439 
[97] Krogstrup P, Jørgensen H I, Heiss M, Demichel O, Holm J V, Aagesen M, Nygard J and Fontcuberta i Morral A 2013 Nature Photo. 7306

[98] Gibson S J, Boulanger J P and LaPierre R R 2013 Semicond. Sci. Technol. 28105025

[99] Sladek K, Haas F, Heidelmann M, Park D, Barthel J, Dorn F, Weirich T E, Grützmacher D and Hardtdgen H $2013 \mathrm{~J}$. Cryst. Growth 370141

[100] Treu J et al 2013 Nano Lett. 136070

[101] Kanungo p D, Schmid H, Björk M T, Gignac L M, Breslin C, Bruley J, Bessire C D and Riel H 2013 Nanotechnology 24225304

[102] Tomioka K and Fukui T 2013 ECS Trans. 5899

[103] Ng k W, Ko W S, Tran T-T D, Chen R, Nazarenko M V, Lu F, Dubrovskii V G, Kamp M, Forchel A and Chang-Hasnain C J 2013 ACS Nano 7100

[104] Hou J J, Wang F, Han N, Zhu H, Fok K, Lam W, Yip S, Hung T, Lee J E-Y and Ho J C 2013 Appl. Phys. Lett. 102093112

[105] Nazarenko M V, Sibirev N V, Ng K W, Ren F, Ko W S, Dubrovskii V G and Chang-Hasnain C 2013 Appl. Phys. Lett. 113104311

[106] Shin J C, Kim D Y, Lee A, Kim H J, Kim J H, Choi W J, Kim H-S and Choi K J 2013 J. Cryst. Growth 37215

[107] Ng K W, Tran T-T D, Ko W S, Chen R, Lu F and Chang-Hasnain C J 2013 Nano Lett. 135931

[108] Ren F, Ng K W, Li K, Sun H and Chang-Hasnain C J 2013 Appl. Phys. Lett. 102012115

[109] Naji K, Saint-Girons G, Penuelas J, Patriarche G, Largeau L, Dumont H, Rojo-Romeo P and Gendry M 2013 Appl. Phys. Lett. 102243113

[110] Wang Z et al 2013 Nano Lett. 135063

[111] Hadj Alouane M H, Chauvin N, Kgmissi H, Naji K, Ilahi B, Maaref H, Patriarche G, Gendry M and Bru-Chevallier C 2013 Nanotechnology 24035704

[112] Fonseka H A, Tan H H, Wong-Leung J, Kang J H, Parkinson $P$ and Jagadish C 2013 Nanotechnology 24465602

[113] Shin j C, Lee A, Mohseni P K, Kim D Y, Yu L, Kim J H, Kim H J, Choi W J, Wasserman D and Choi K J and Li X 2013 ACS Nano 75463

[114] Zhang Y, Aagesen M, Holm J V, Jørgensen H I, Wu J and Liu H 2013 Nano Lett. 133879

[115] Holm J V, Jørgensen H I, Krogstrup P, Nygård J, Liu H and Aagesen M 2013 Nature Commun. 41498

[116] Alarcón-Lladó E, Conesa-Boj S, Wallart X, Caroff P and Fontcuberta i Morral A 2013 Nanotechnology 24405707

[117] Yang Z-X, Han N, Wang F, Cheung H-Y, Shi X, Yip S, Hung T, Lee M H, Wong C-Y and Ho J C 2013 Nanoscale 59671

[118] Núňez C G, Brana A F, pau J L, Ghita D, Garcia B J, Shen G, Willbert D S, Kim S H and Kung P 2014 J. Appl. Phys. 115034307

[119] Munshi A M et al 2014 Nano Lett. 14960

[120] Tomioka K and Fukui T 2014 Appl. Phys. Lett. 104073507

[121] Koblmüller G and Abstreiter G 2014 Phys. Status Solidi PRL 811
[122] Norris k J, Zhang J, Fryauf D M, Gibson G A, Barcelo S J and Kobayashi N P 2014 J. Cryst. Growth 386107

[123] Li K, Sun H, Ren F, Ng K W, Tran T-T D, Chen R and Chang-Hasnain C J 2014 Nano Lett. 14183

[124] Jing Y, Bao X, Wei W, Li C, Sun K, Aplin D P R, Ding Y, Wang Z-L, Bando Y and Wang D 2014 J. Phys. Chem. C 1181696

[125] Conesa-Boj S, Kriegner D, Han X-L, Plissard S, Walalrt X, Stangl J, Fontcuberta i Morral A and Caroff P 2014 Nano Lett. 14326

[126] Heiss M, Russo-Averchi E, Dalmau-Mallorqui A, Tütüncüoğlu G, Matteini F, Rüffer D, Conesa-Boj S, Demichel O, Alarcon-Lladó E and Fontcuberta i Morral A 2014 Nanotechnology 25014015

[127] Hocevar M, Immink G, Verheijen M, Akopian N, Zwillr V, Kouwenhoven L and Bakkers E 2012 Nature Commun. 31266

[128] Hillerich K, Dick K A, Wen C-Y, Reuter M C, Kodambaka S and Ross F M 2013 Nano Lett. 13903

[129] Conesa-Boj S, Dunand S, Russo-Averchi E, Heiss M, Ruffer D, Wyrsch N, Ballif C and Fontcuberta i Morral A 2013 Nanoscale 59633

[130] Tomioka K, Yoshimura M and Fukui T 2013 Nano Lett. 135822

[131] Tomioka K, Motohisa J, Hara S and Fukui T 2008 Nano Lett. 83475

[132] Tomioka K, Kobayashi Y, Motohisa J, Hara S and Fukui T 2009 Nanotechnology 20145302

[133] Wieder H H 2003 J. Vac. Sci. Technol. B 211915

[134] Galindo P L, Kret S, Sanchez A M, Laval J-Y, Yáňez A, Pizzaro J, Guerrero E, Ben T and Molina S I 2007 Ultramicroscopy 1071186

[135] Takato H et al 1991 IEEE Trans. Electron Devices 38573

[136] Bohr M 2011 IEEE IEDM Technical Digest 1

[137] Ng H T, Han J, Yamada T, Nhuyen P, Chen Y, Meyyappan M 2004 Nano Lett. 41247

[138] Bryllert T, Wernersson L-E, Fröberg L E, Samuelson L 2006 IEEE Electron Device Lett. 27323

[139] Tomioka K, Yoshimura M, Fukui T 2013 IEEE DRC Conf. Digest 15

[140] Ferrain I, Colinge A A and Conlinge J-P 2011 Nature 479310

[141] ITRS 2011 International Technology Roadmap for Semiconductors www.itrs.net/Links/ 2011ITRS/Home2011.htm

[142] Tomioka K, Yoshimura M and Fukui T 2011 IEEE VLSI Symposia Technical Digest 47

[143] Seabaugh A C and Zhang Q 2010 Proc. IEEE 982095

[144] Riel H, Moselund K E, Bessire C, Björk M T, Schenk A, Ghoneim H and Schmid H 2012 IEEE IEDM Technical Digest 16

[145] Tomioka K, Mohan P, Noborisaka J, Hara S, Motohisa J and Fukui T 2007 J. Cryst. Growth 298644 